\title{
Research Square \\ Manufacturing large shafts by a novel flexible skew rolling process
}

\section{Longfei Lin ( $\nabla$ colin0910@foxmail.com )}

University of Science and Technology Beijing https://orcid.org/0000-0001-5513-3829

\section{Baoyu Wang}

University of Science and Technology Beijing

Jing Zhou

University of Science and Technology Beijing

Jinxia Shen

University of Science and Technology Beijing

\section{Research Article}

Keywords: Flexible skew rolling, Large shafts rolling, Forming defects, Forming precision, Feasibility study

Posted Date: May 13th, 2021

DOI: https://doi.org/10.21203/rs.3.rs-508796/v1

License: (9) This work is licensed under a Creative Commons Attribution 4.0 International License. Read Full License

Version of Record: A version of this preprint was published at The International Journal of Advanced Manufacturing Technology on October 5th, 2021. See the published version at https://doi.org/10.1007/s00170-021-08079-y. 
3 a School of Mechanical Engineering, University of Science and Technology Beijing,

4 Beijing 100083, China

$5 \quad{ }^{b}$ Beijing Laboratory of Metallic Materials and Processing for Modern Transportation,

$6 \quad$ Beijing 100083, China

$7 \quad *$ Corresponding author: Baoyu Wang

$8 \quad$ E-mail address: bywang@ustb.edu.cn

9 Tel: $+86-010-82375671$

$10 \quad$ Fax: $+86-010-82375671$

11 Postal address: No.30 Xueyuan Road, Haidian District, Beijing 100083, China 12 

precision, Feasibility study

\section{Abstract}

When manufacturing large shafts with multi-specification and small-batch production, both the conventional forging and rolling process bring a high tooling cost due to heavy forging press or large-size specialized roller. In this study, a novel flexible skew rolling (FSR) process is proposed by adding degrees of freedom to the rollers as compared to the typical skew rolling process. Since each of the FSR rollers has three degrees of freedom (circle rotating, radial rotating and radial feeding), the FSR process can be divided into four stages: radial rolling, rollers inclining, skew rolling and rollers levelling. Therefore, the FSR process can produce various shafts with same rollers via programming different movements. To verify the feasibility of FSR process, a physical investigation corresponding with a numerical simulation for a single-step shaft is undertaken with a $\Phi 80 \times 390 \mathrm{~mm} \mathrm{C45}$ steel billet. According to the results from physical experiments and numerical simulations, the FSR formed shaft has a maximum deviation of $0.99 \mathrm{~mm}$, and its microstructure and properties have been improved obviously. Moreover, although there is a tendency of center crack in FSR products as predicted by numerical results, both the transverse and longitudinal section of the physical shaft are free from central cracking. The major forming defects existed on the rolled shaft are knurled pockmarks, surface threads and side cavity, which are the typical defects of the conventional skew rolling and cross-wedge rolling and can be removed by machining. To the authors' knowledge, this novel process has a good combination of flexible production and less loading, which will be of great engineering significance to reduce the tooling cost in large shafts manufacturing. 


\section{Introduction}

Large shafts play an important role in large-elongated axial parts manufacturing and die-forging billets preforming, which are widely used on transportation vehicle, aerospace, construction machinery and other indutrial clusters, such as railway axles [1, 2], truck shafts [3], preform of turbine blade [4] and railway switch [5]. Up to now, these shafts are generally formed by forging process (open die forging [6, 7], radial forging $[8,9,10])$ and cross-wedge rolling (CWR) process $[1,11,12]$. Nevertheless, the forging process can manufacture various shafts by common rollers but needs a high forging force on account of its characteristic of overall deformation, which results in the heavy tonnage of forging equipment. Conversely, the cross-wedge rolling process can achieve less-loading forming by regional deformation but needs large-size specialized rollers. When manufacturing large shafts in multi-specification and smallbatch production, both the forging and rolling process bring a high tooling cost due to the heavy loading press or the large-size specialized rollers.

In order to achieve flexible manufacturing, a process of axial feed rolling was early proposed and investigated $[13,14]$, whose schematic diagram is shown in Fig. 1a. The workpiece is radially compressed via two rollers feeding radially and whereafter axially stretched under the chuck drawing. Therefore, the axial feed rolling process is a flexible production that same rollers can manufacture various multiple-step parts by different roller movements. However, because two rollers are paralleled with each other, the drawing force of the chuck is significant huge, especially in large shafts manufacturing. 


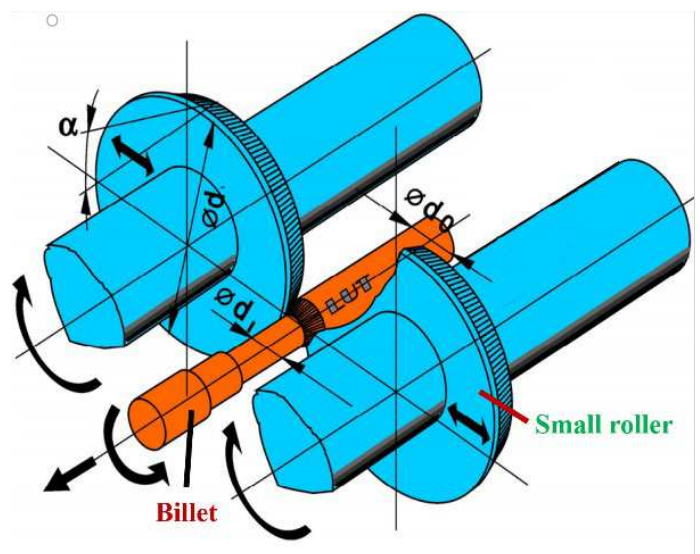

(a) axial feed rolling

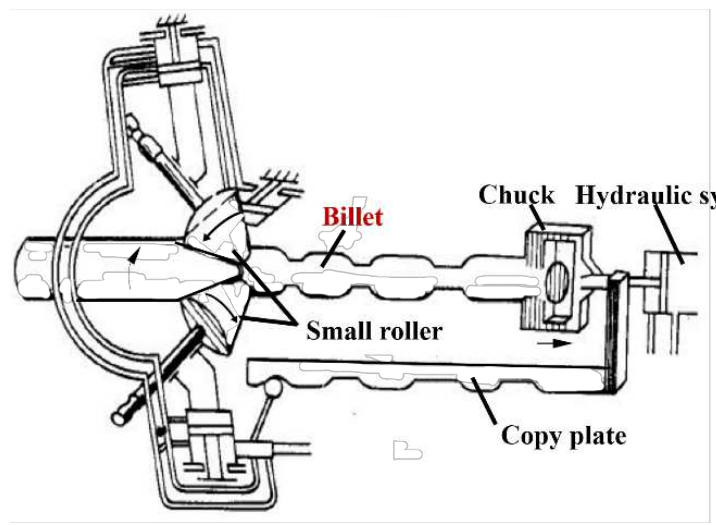

(b) copy skew rolling

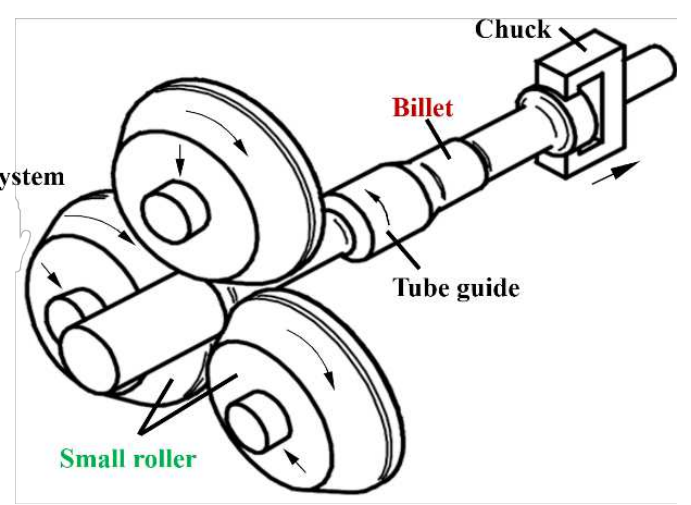

(c) CNC skew rolling

Fig. 1 The existing flexible rolling process for stepped shafts manufacturing

Another flexible rolling process is three-roller skew rolling method which can be divided into two types: copy skew rolling (Fig. 1b) and CNC skew rolling (Fig. 1c). Copy skew rolling is originated from the Soviet Union by Zerikov,1948 [15, 16], in which a copy plate is used to control the motions of tapered rollers. With the development of automatic control technology, Pater et al. $[2,17]$ used a CNC system to replace the copy unit and successfully accomplished the laboratory experiments of forming two rail axles in a CNC skew rolling mill. Significantly, due to the tapered rollers are inclined to each other, the rolling workpiece of copy skew rolling and CNC skew rolling can be automatically driven by the axial component of friction, so that the drawing force of the chuck can be significantly decreased.

Nevertheless, all these mentioned processes, whether in axial feed rolling, copy skew rolling or CNC skew rolling, a chuck is required to draw the workpiece in axial direction that may cause the limitations of :1) a considerable amount of chucking 
allowance is indispensable that the material utilization is reduced; 2) the maximum length of the rolled shaft is limited by the chuck stroke of the mill. By far, all these flexible rolling methods are not seen in extensive application.

In this study, a novel flexible skew rolling (FSR) process is proposed by adding degrees of freedom to the rollers as compared to the typical skew rolling process. The aim of this presented paper is to verify the flexibility of this novel FSR process. Firstly, new type of FSR mill and FSR roller are designed, and their features are detailly introduced. Secondly, an FSR experiment of a $\Phi 80$ single-step shaft is performed to verify the feasibility of FSR process. Thirdly, a corresponding finite element (FE) numerical simulation are conducted to reveal the FSR deformation characteristic. At last, several types of physical experiments are performed to explore the FSR applications and reveal the FSR forming defects.

\section{Flexible skew rolling (FSR) process}

\subsection{Novel process of flexible skew rolling}

As shown in Fig. 2, a two-roller FSR process is invented by the authors [18]. Its rolling device mainly consists of two rollers and two tube guides. Each of two rollers has three degrees of freedom as circumferential rotating $N_{0}$, radial feeding $V_{0}$ and angle adjusting $W_{0}$. Two tube guides are respectively fixed on the sides of two rollers to restrict the movements of workpiece. By programming the motions $\left(N_{0}, V_{0}, W_{0}\right)$ of two rollers in an automatic system, the FSR process can be divided into four stages (Fig. 2b): 1) radial rolling: two leveled rollers have the motions of $N_{0}$ and $V_{0}$, and then two rollers knife into the workpiece; 2) rollers inclining: two rollers only have the motion of $W_{0}$, and the skewing angle $\beta$ is increased to target value; 3 ) skew rolling: two inclined rollers only have the motion of $N_{0}$, and the workpiece rotates circularly and moves axially; 4) rollers levelling: two rollers have the motions of $V_{0}$ and $W_{0}$, and then back to the original state.

Since the FSR process can be programmed into four stages, the FSR process can 
flexibly form various shafts with same rollers. And according to the above descriptions,

121 the FSR method has the following characteristics: 1) a drawing chuck is unessential 122 because the workpiece can move axially under the action of axial friction; 2) the rolling 123 equipment is relatively simple because only two rollers are needed; 3) an automated 124 system is essential because the movements of two rollers is much complex and difficult 125 to control.

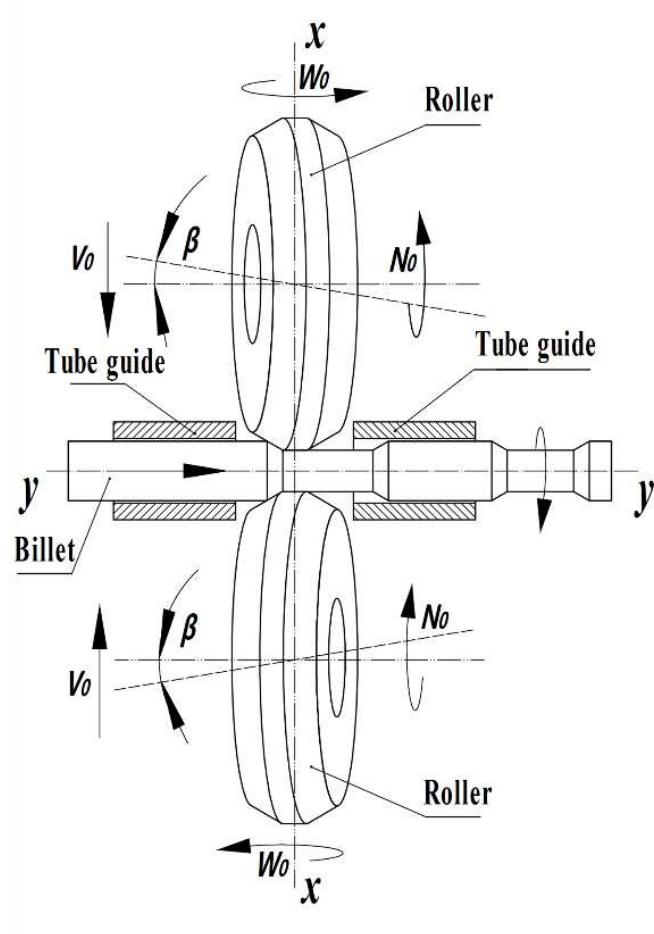

(a)

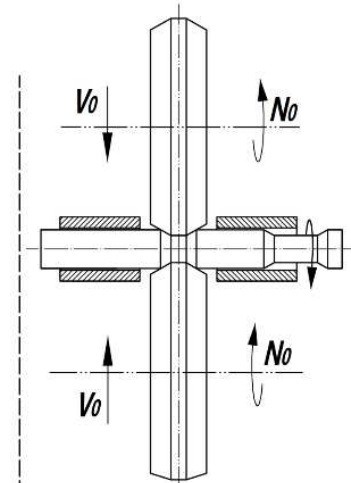

Radial rolling

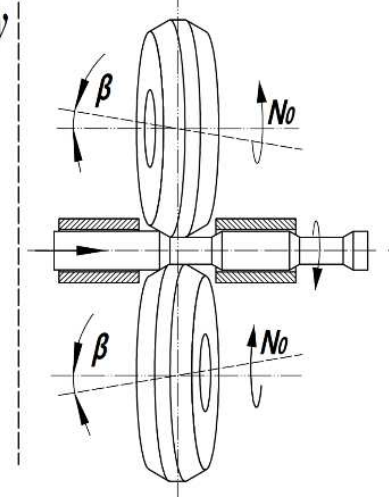

Skew rolling
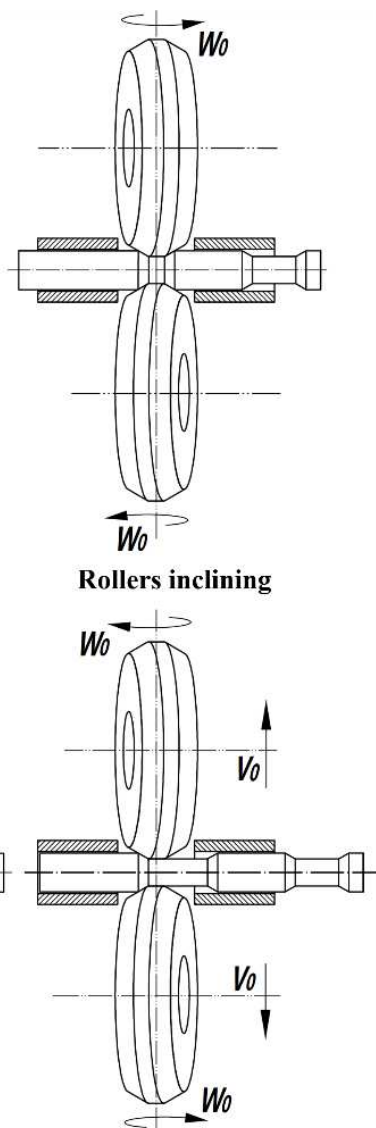

Rollers levelling

(b)

Fig. 2 Schematic illustration of flexible skew rolling (FSR): (a) process principle; (b) rolling stages [18]

\subsection{New type of FSR mill and FSR roller}

Because the FSR process is a new method, the design of FSR mill and roller is a critical job, and a number of attempts have been made. To meet the requirement of the FSR process, a laboratory FSR mill which has three degrees of freedom $\left(N_{0}, V_{0}, W_{0}\right)$ is indispensable. Therefore, a new type of multi-freedom rolling mill has been invented and constructed [19]. Its 3D model is shown in Fig. 3. The physical mill is presented in 
Fig. 4, and technical specifications are given in Table. 1. The FSR mill mainly consists

136 of ten components: a base unit -1 , two tube guides -2 , two arm stands -3 , two angle 137 adjusting systems -4 , two rollers -5 , two rotating systems -6 , a counter balance unit $138-7$, a radial feeding system -8 , a synchronous unit -9 , and a servo control system.

139 In the FSR mill, two rotating systems are correspondenly mounted under two arm 140 stands and drive two rollers rotating around its axle. Two angle adjusting systems are 141 fixed on the two arm stands to adjust the skewing angle, respectively. In order to make 142 the radial feeding system synchronous, a synchronous unit worked by two matched 143 gears is used to ensure two arm stands open or close together. What need to pay 144 attention to is that, the overall dimension of this mill is $1.8 \mathrm{~m} \times 1.7 \mathrm{~m} \times 1.6 \mathrm{~m}$ and its total 145 power is $70 \mathrm{~kW}$, but the maximum billet diameter can up to $80 \mathrm{~mm}$. We can have a 146 conclusion that the FSR mill has a advantage of compactness structure.

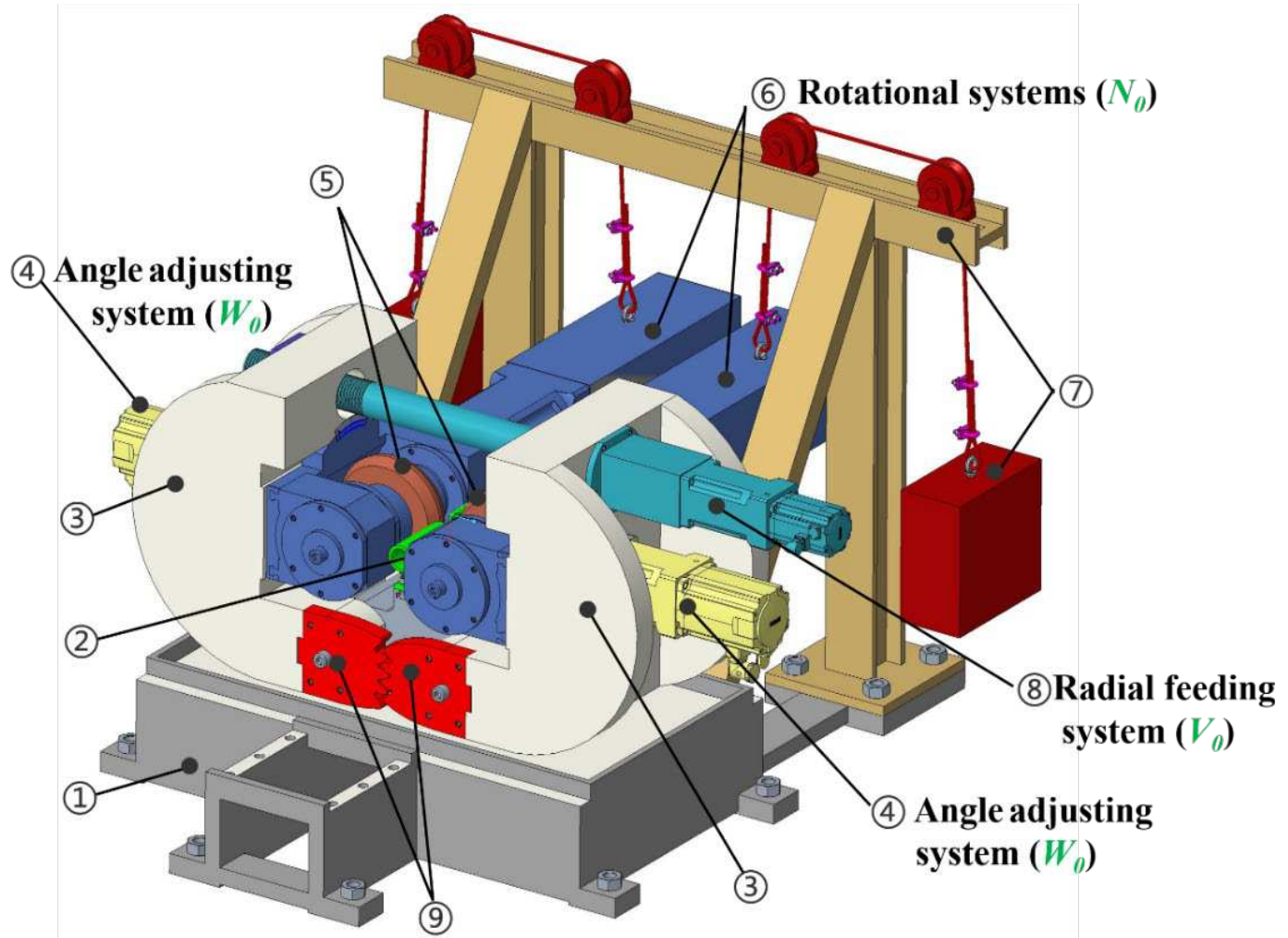

Fig. 3 3D geometrical model of FSR mill [19] 


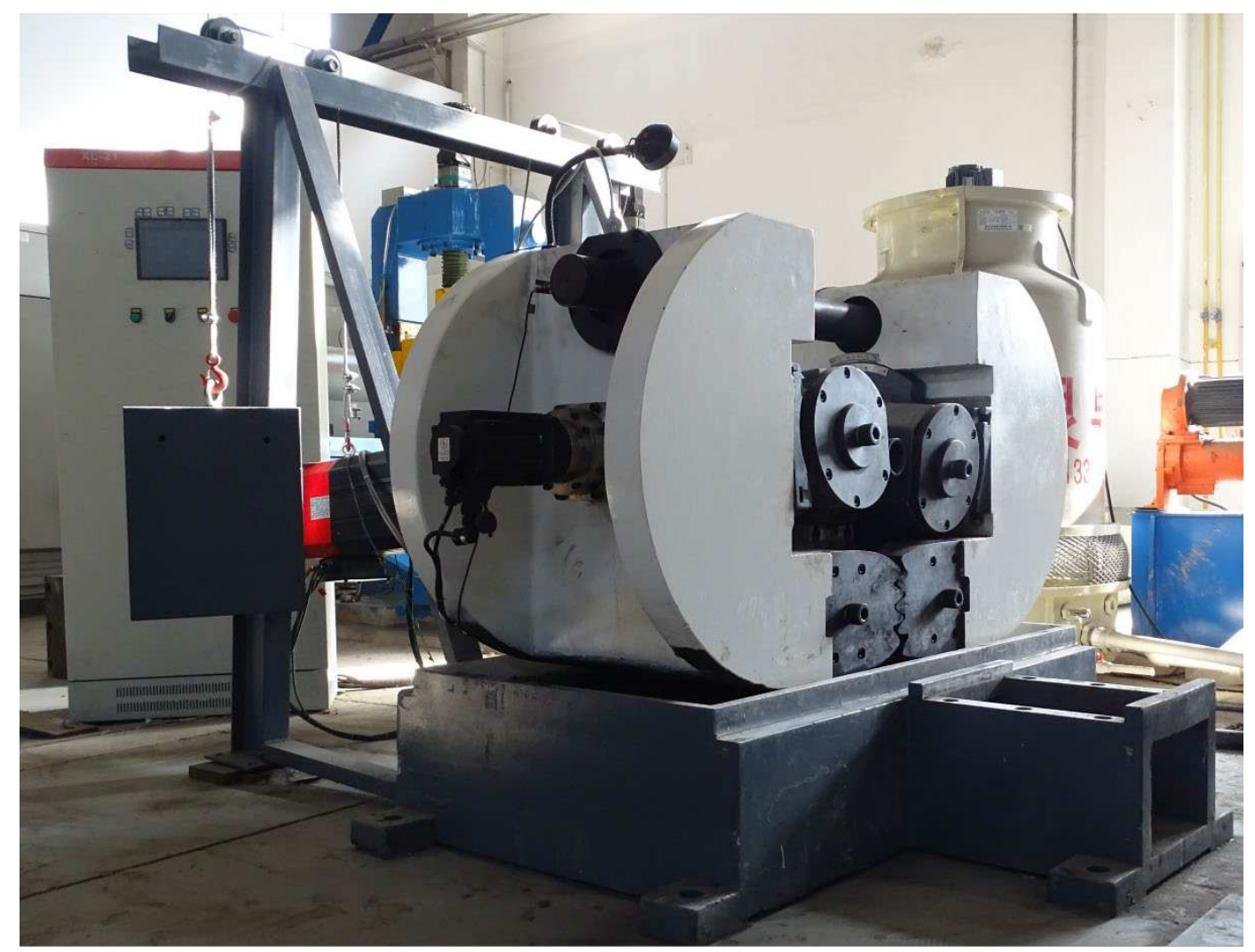

Fig. 4 A physical FSR mill was invented and constructed [19]

151

152

Table.1 Technical specifications of FSR mill

\begin{tabular}{lcc}
\hline Parameter & Unit & Value \\
\hline Main rotating motor power & $\mathrm{kW}$ & $2 \times 30$ \\
Main rotating speed & $\mathrm{rpm}$ & $0 \sim 43$ \\
Radial feeding motor power & $\mathrm{kW}$ & 3 \\
Radial feeding speed & $\mathrm{mm} / \mathrm{s}$ & $1 \sim 5$ \\
Angle adjusting motor power & $\mathrm{kW}$ & $2 \times 2.3$ \\
Angle adjusting speed & $\circ / \mathrm{s}$ & $1 \sim 10$ \\
Angle adjusting range & $\circ$ & \pm 12 \\
Rolling center line range & $\mathrm{mm}$ & \pm 0.15 \\
Maximum roller diameter & $\mathrm{mm}$ & 350 \\
Maximum billet diameter & $\mathrm{mm}$ & 80 \\
Overall dimensions & $\mathrm{m}$ & $1.8 \times 1.7 \times 1.6$ \\
Total power & $\mathrm{kW}$ & 70 \\
Total weight & ton & 5 \\
\hline
\end{tabular}


The FSR roller is inspired by the piercing roller [20] but has some developments

156 because all the forming stages need to be considered and the workpiece needs to avoid

157 crack. The FSR roller is shown in Fig. 5 and has a small size and a simple shape. It has

158 a symmetrical structure of a sizing zone in the middle and two forming zones on both

159 sides because the rolling force should be balanced in axis direction during the radial 160 rolling stage. In addition, it is made by hot-die-material H13 and its hardness is 161 measured as $53 \mathrm{HRC}$. Besides, the forming zone surface is knured by a $2 \mathrm{~mm}$ hatching 162 knurling knife (CN standard, GB 6403.3) to improve the FSR rolling conditions. The 163 geometric parameters of FSR rollers are: diameter $D_{0}=340 \mathrm{~mm}$, length $L_{0}=120 \mathrm{~mm}$, 164 forming angle $\alpha=20^{\circ}$ and sizing width $L=25 \mathrm{~mm}$.

165

166

167

168

169

170

171

172

173

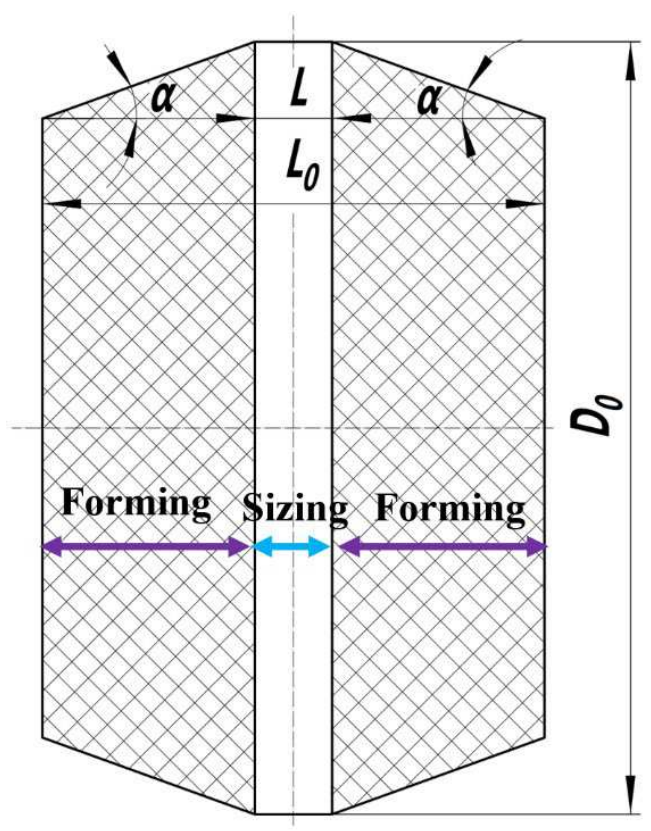

(a)

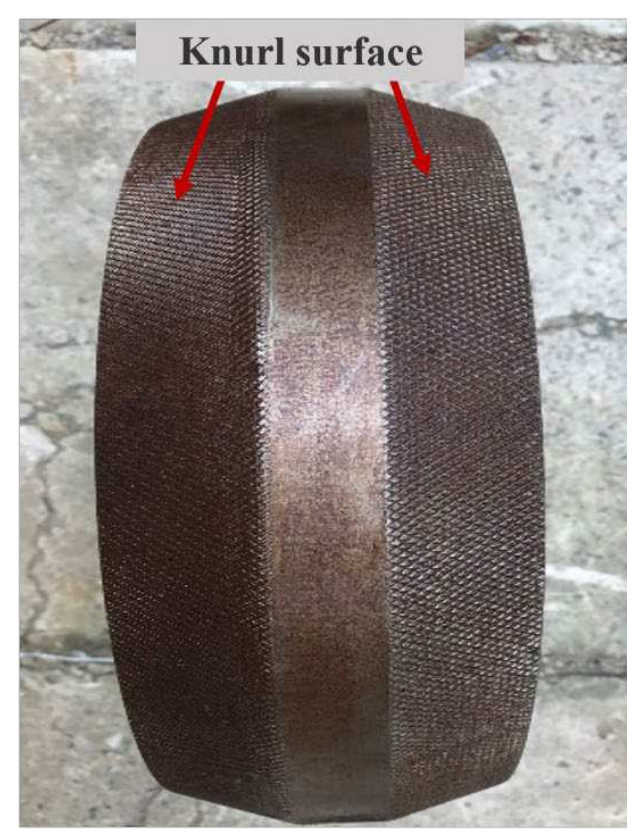

(b)

Fig.5 New type of FSR roller: (a) geometric model; (b) physical graphics

\section{Feasibility experiment of a $\Phi 80$ single-step shaft FSR rolling}

\subsection{FSR rolling experiment}

To verify the feasibility of the FSR process, a physical feasibility experiment of a single-step shaft FSR rolling was undertaken with a $\Phi 80 \times 390 \mathrm{~mm}$ C45 steel billet. The physical experiment was performed at the University of Science and Technology Beijing, China. Because the rolled shaft only has one step, the FSR rolling process 
174 simply includes three stages of radial rolling, rollers inclining and skew rolling.

175 Although not all processes are included, two main forming stages (radial rolling, skew

176 rolling) are totally covered. Therefore, it can be concluded that the feasibility 177 experiment is reasonable.

178 The flow chart of rollers' movements is shown in Fig. 6. At the radial rolling stage, 179 two leveled rollers rotate with a constant speed of $N_{0}=30 \mathrm{rpm}$ and feed radially with a 180 speed of $V_{0}=1.5 \mathrm{~mm} / \mathrm{s}$. After the radial rolling stage ( 10 seconds later), the gap between

181 two rollers reaches the target value of $50 \mathrm{~mm}$. During the rollers inclining stage, the 182 inclining angles of two rollers are adjusted into a skewing angle of $\beta=8^{\circ}$. At the skew 183 rolling stage, two rollers remain an inclined angle $\beta=8^{\circ}$ and rotate at the speed of $184 \mathrm{~N} 0=30 \mathrm{rpm}$, and the workpiece rotates circumferentially and moves axially under the 185 frictional force.

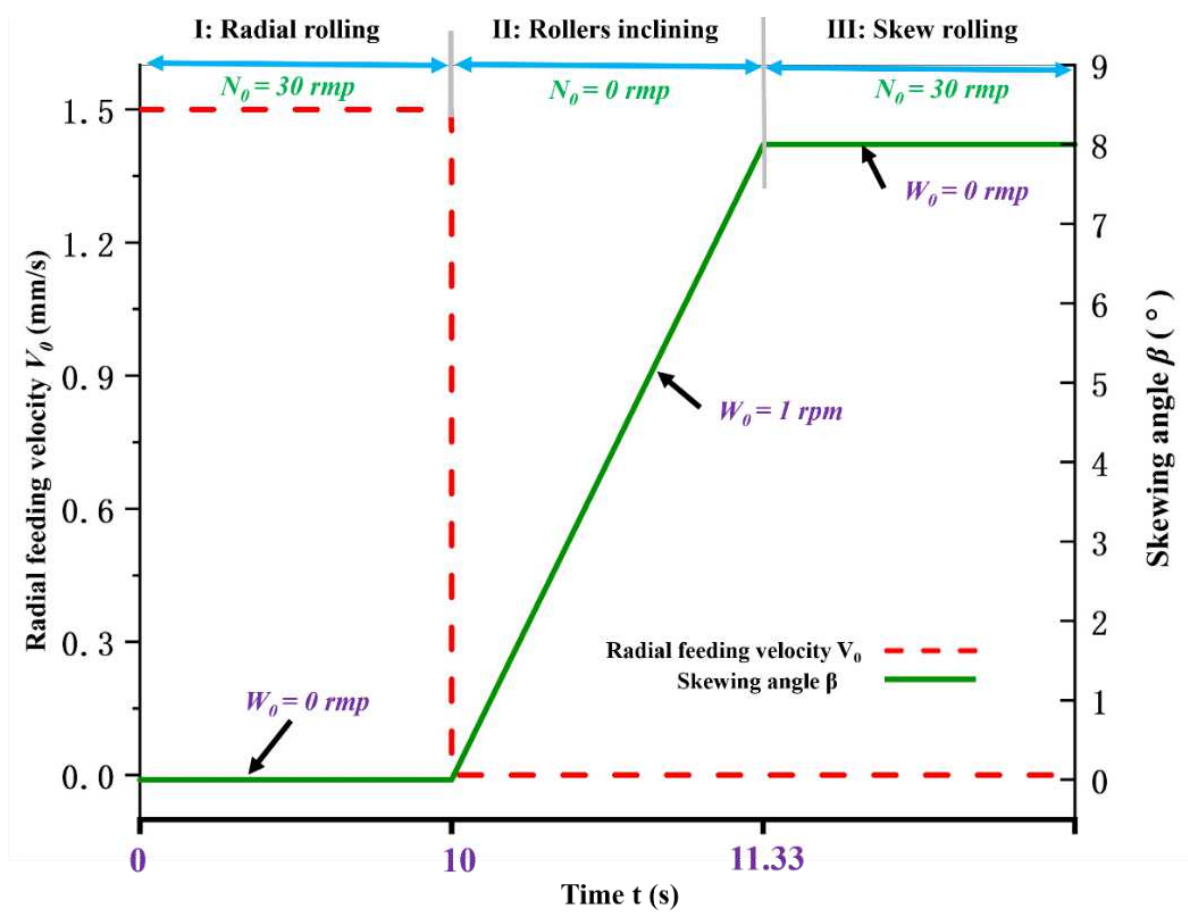

Fig. 6 Schematic diagrams of the movements of FSR rollers

Prior to the rolling, the billet was preheated to $1050^{\circ} \mathrm{C}$ in an electric tube furnace and then immediately transferred to the FSR mill. As shown in Fig. 7, The workpiece was rolled stably during every stage. After FSR rolling, the product was removed and

191 cooled in the air. The rolled shaft is shown in Fig. 8, whose cross-section shrinkage is exceeded $60 \%$. 

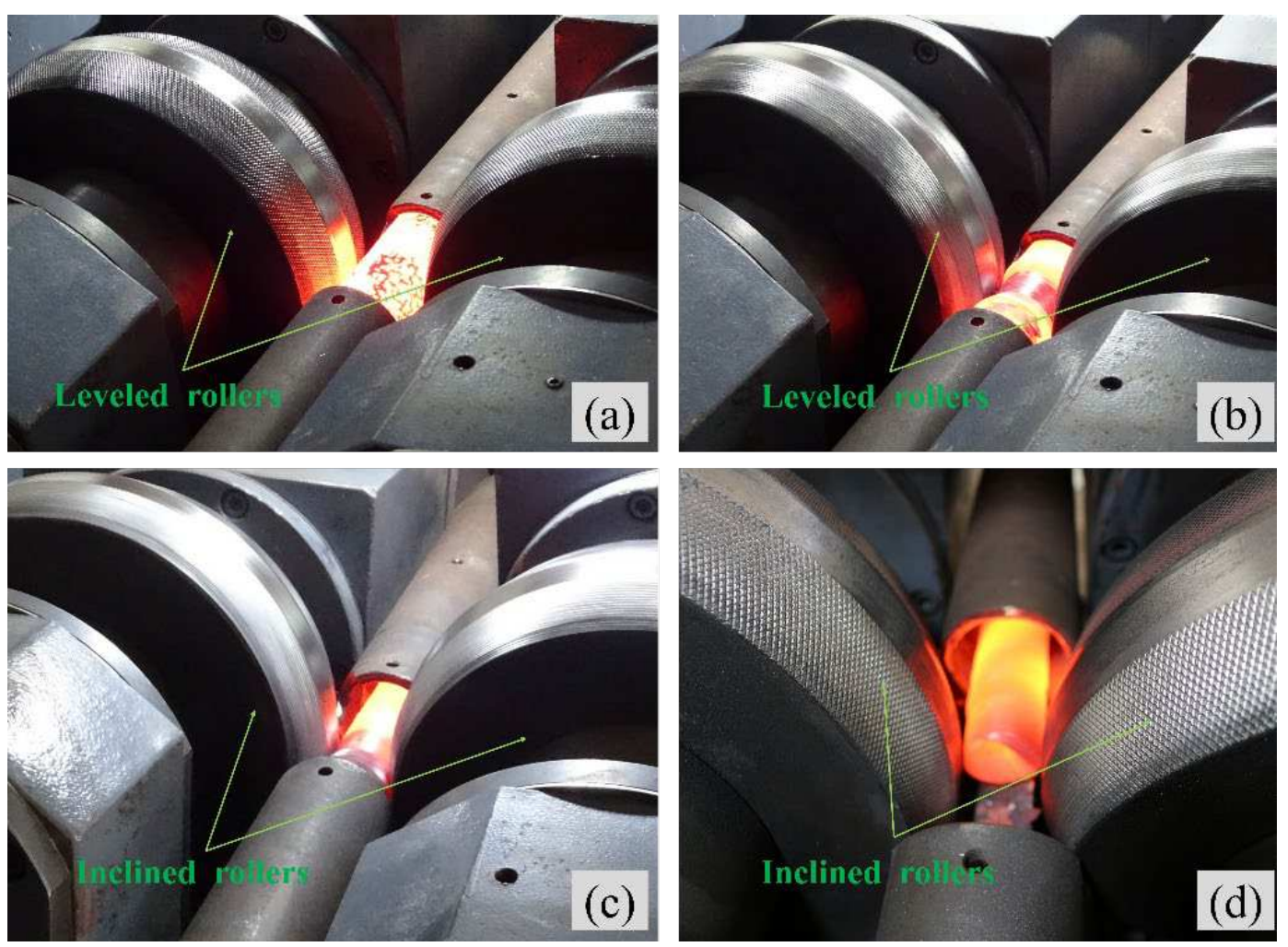

Fig. 7 FSR experiment for a $\Phi 80$ single-step shaft: (a) beginning of radial rolling stage; (b) during radial rolling stage; (c) during skew rolling stage; (d) ending

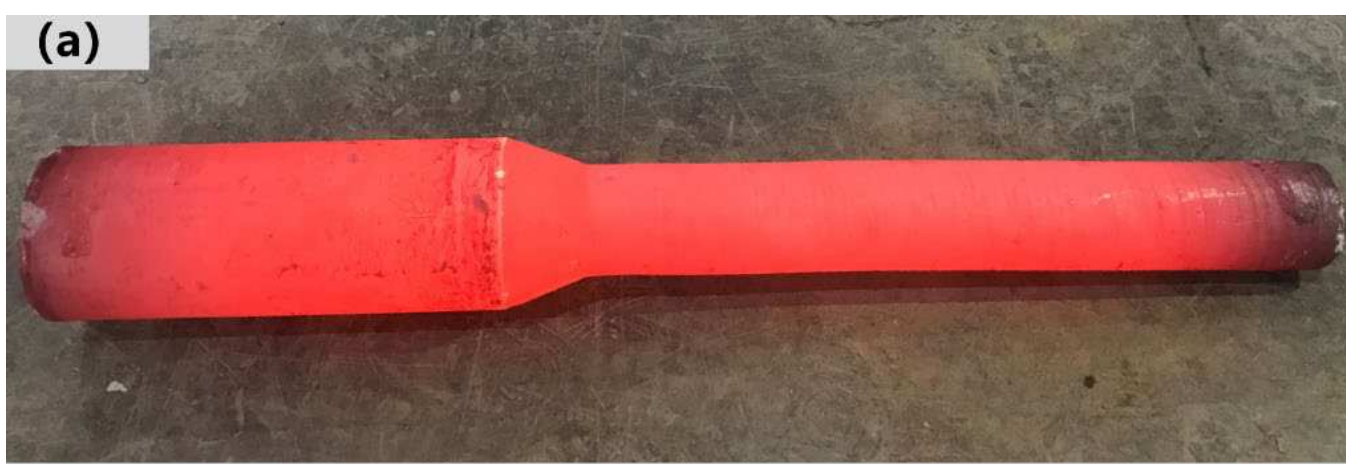

\section{(b)}

Fig. 8 A $\Phi 80$ mm single-step shaft was produced by FSR process: (a) just finished rolling; (b) after cooled at room temperature

200 feasible and optimistic; 2) the complex motions of rollers can be precisely regulated by

201 FSR mill and the technical specifications of FSR mill are sufficient; 3) the temperature

202 of the workpiece is relatively stable and still in the temperature range of hot deformation. 


\subsection{Results and discussion}

204

205

206

207

208

209

210

211

\subsubsection{Forming precision}

The geometrical dimension of the FSR shaft was acquired by a high precision 3D scanner and then measured in Geomagic Quality software. As Fig. 9 shows, at radial rolling stage, the maximum and minimum diameter deviations of the FSR rolled shaft are $+0.8 \mathrm{~mm}$ and $-0.39 \mathrm{~mm}$. Respectively, these of skew rolling stage are $+0.99 \mathrm{~mm}$ and $-0.35 \mathrm{~mm}$. To do an analysis, because the workpiece is restricted by two tube guides, the rolled shaft does not bend easily, so that the diameter deviations mainly result from the surface threads.

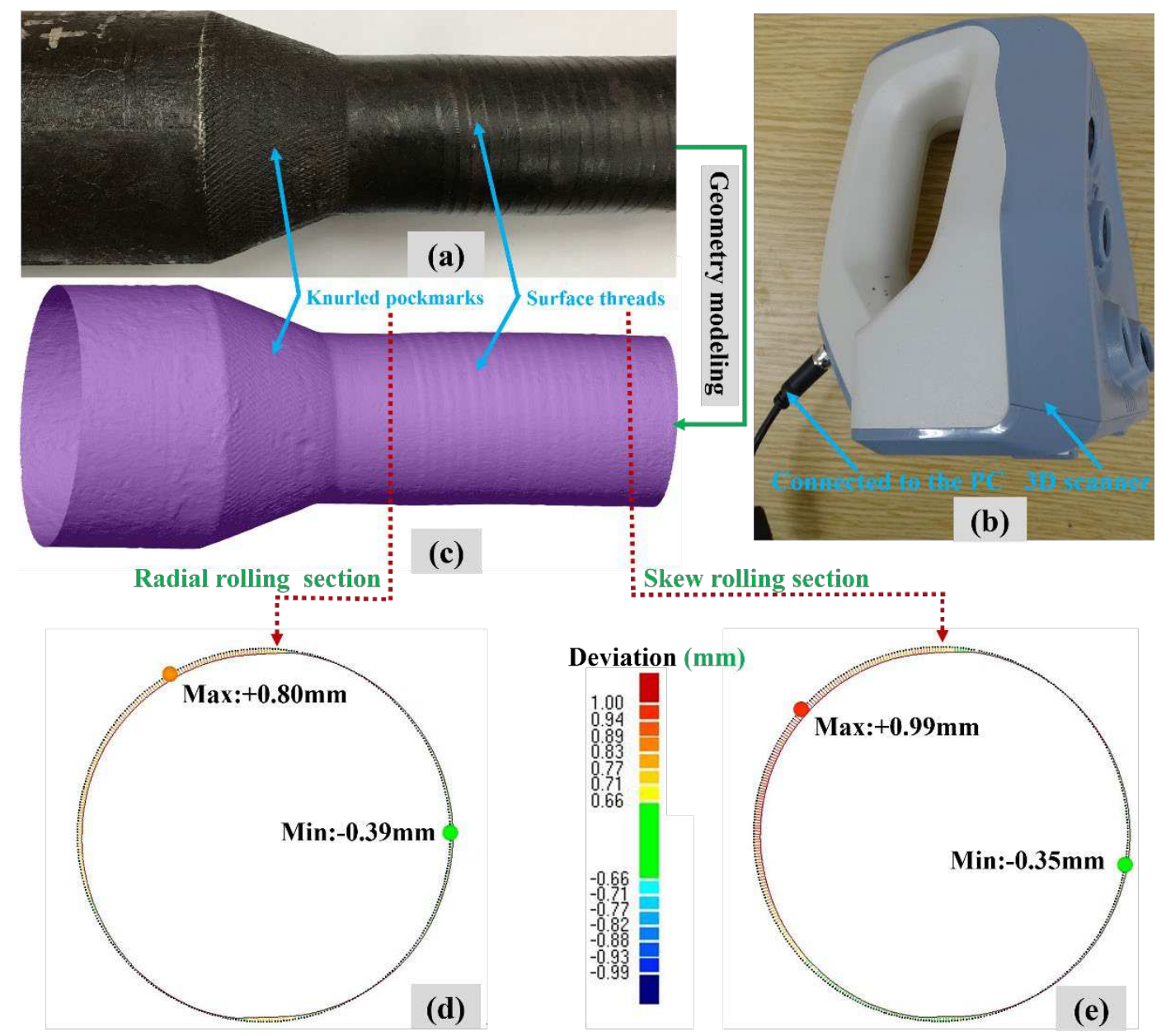

213 Fig. 9 The (c) geometric model of the (a) rolled shaft was modeled by a high 214 precision (b) 3D scanner and their (d, e) dimensional deviations were measured. 
There are some forming defects appeared on the rolled-shaft as shown in Fig.9a.

217 The knurled pockmarks exist on the step surface because the rollers' surfaces were

218 knurled by hatching knurling. In addition, the surface threads, which are formed at the

219 stage of skew rolling, obviously present on the rolled rod. The main reason for these

220 surface threads may be that the sizing length $L$ is too short or the chamfering angle

221 between the forming and sizing zone of the roller is unreasonable, thus futher research

222 is necessary.

223 Another observed defect is the side cavity as shown in Fig.10b, which has a length 224 of $36.8 \mathrm{~mm}$ and an angle of $61.2^{\circ}$. It can be explained that the material of the outer 225 sphere flows more rapid than that of the internal. This defect leads to the waste of the 226 material, but does not affect the quality of products.

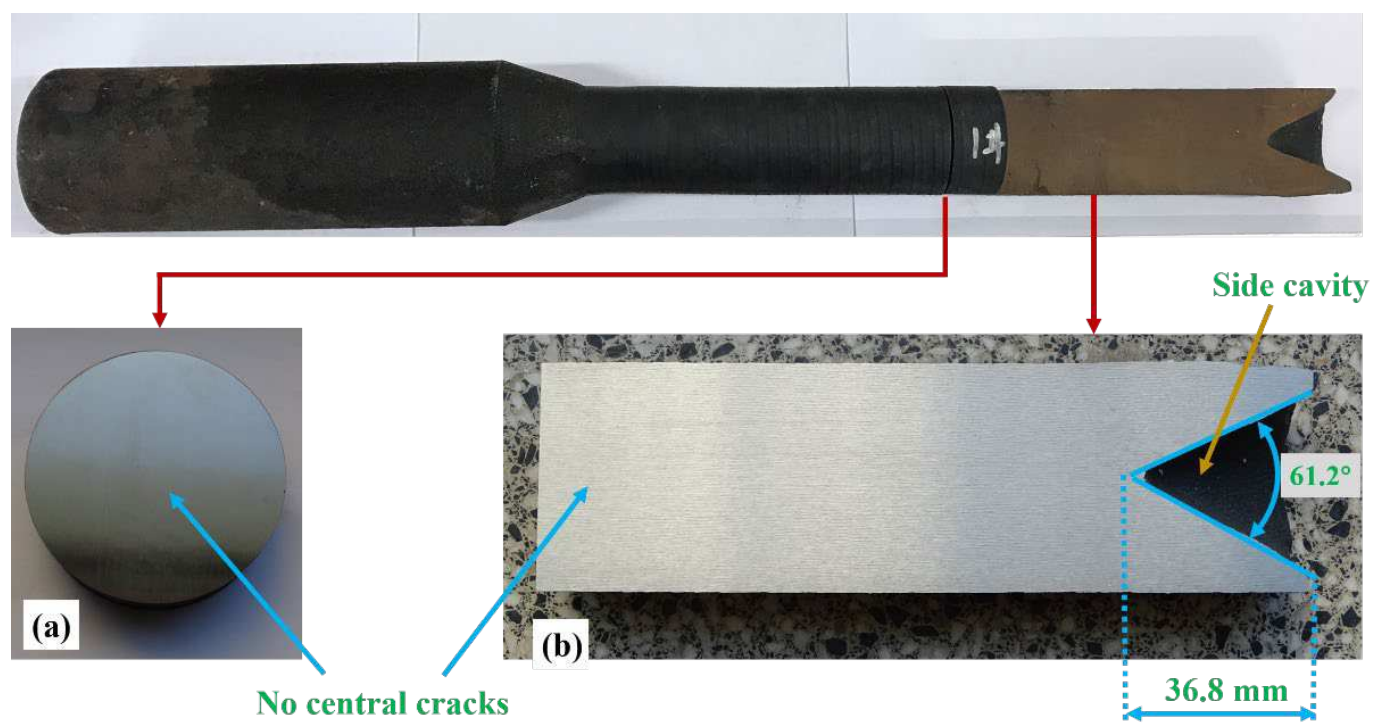

Fig. 10 FSR rolled shaft has the defect of side cavity and free from central cracks in macroscale: (a) transverse section; (b) longitudinal section

Actually, all these observed defects are the typical imperfections in skew rolling $[2,17,21]$ and cross-wedge rolling $[22,23,24]$ and can be removed in later precision machining, so do not affect the quality of produced shaft.

\subsubsection{Central quality}

Since the skew rolling stage of FSR process is much similar to the piercing process which has the trend of central cracking, we can estimate that, the central cracks, also 
236 called the Mannesmann effect [25], may occur in the workpiece central and reduce the 237 performance of formed parts.

238 For a observation in detail, both the transverse and longitudinal section of the FSR 239 rolled shaft has been polished. As demonstrated in Fig. 10, it is clearly shown that the 240 rolled shaft is free from any internal defects in the macroscale. Furthermore, its micro241 morphology is observed by a 200 times magnification in the optical microscope. As 242 shown in Fig. 11d, the magnified center is free from visible cracks or holes, which 243 furtherly indicate the $\Phi 80 \mathrm{~mm}$ single-step shaft has no center crack.

\section{$244 \quad$ 3.3.3 Microstructure evolution}

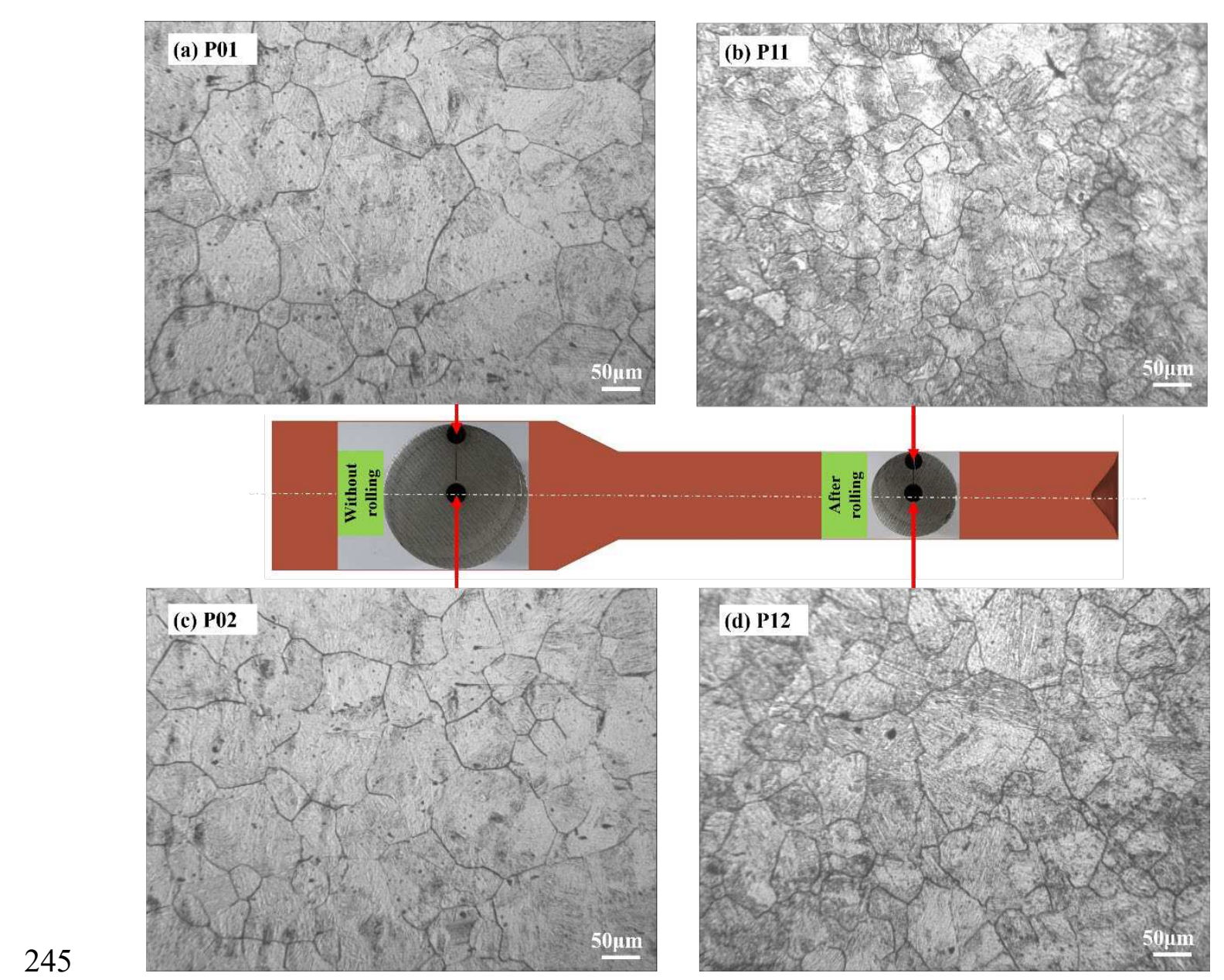

Fig. 11 Micromorphology of FSR rolled shaft at different locations (without visible cracks) 
250 four samples named P01, P02, P11 and P12 were chosen from the outer and inner region

251 of the unrolled and rolled rod. These samples were polished and etched, and their grains

252 size and micro-morphology was obtained in a microscope with 200 times magnification.

253 As Fig. 11 shows, the grain sizes of rolled samples $(\mathrm{P} 11, \mathrm{P} 12)$ are smaller than that

254 of unrolled samples (P01,P02), it can be explained that the grains in outer and inner

255 regions are refined by FSR rolling. Besides, the grains of the outer zone (P11) are

256 obviously refined much greater than these of the inner (P11) because the outer materials

257 have a much larger plastic deformation than central. All these observed results

258 demonstrate that workpiece microstructures can be improved by the FSR process.

259

260

261

262

263

264

265

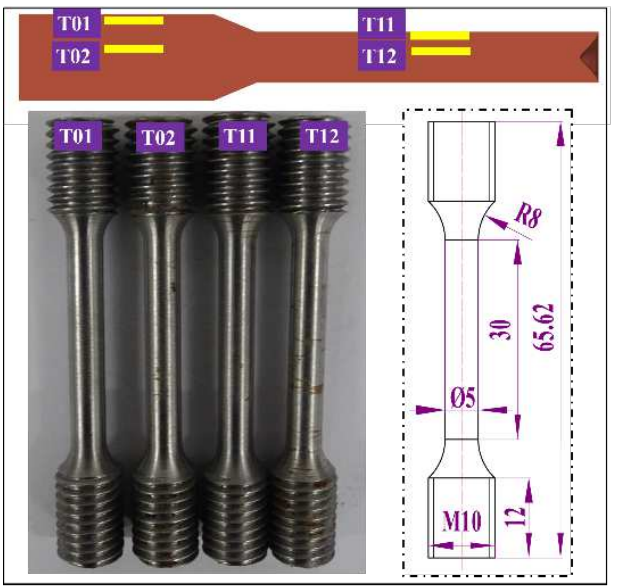

(a)

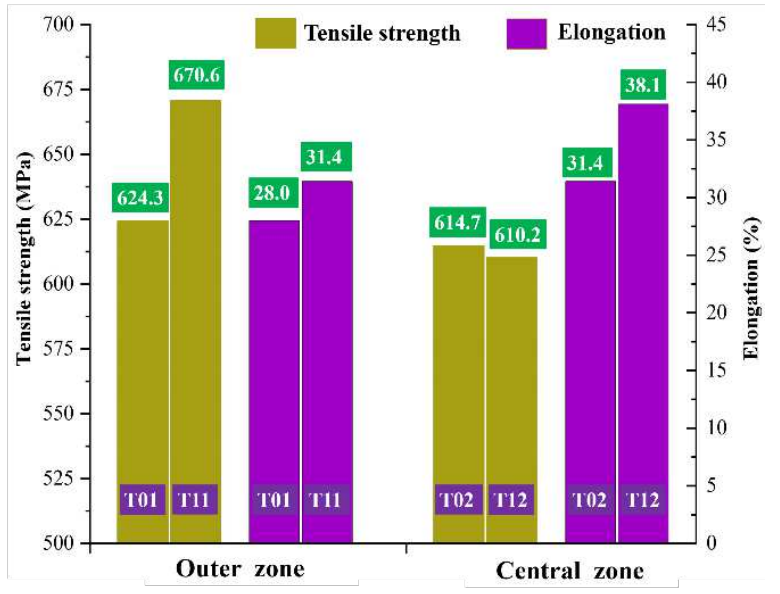

(b)

Fig. 12 Mechanical properties of FSR rolled shaft at different locations: (a) positions and dimensions of the tensiled samples; (b) the results of tension tests

In the outer zone, the UTS is significantly enhanced from $624.3 \mathrm{MPa}$ to $670.6 \mathrm{MPa}$ and the elongation is increased from $28.0 \%$ to $31.4 \%$. However, in the center of the 
271 shaft, the UTS is slightly reduced and the elongation is significantly improved. These

272 performances can be explained that the outer materials have experienced a larger

273 deformation that the outer grains are greater refined than the inner. As for the UTS slight

274 decrease in the central zone, we can think that, the rolled bar has a smaller diameter and

275 therefore the faster temperature drops cause the tensile strength increase. But in general,

276 the overall mechanical properties of the whole shaft are improved after FSR 277 deformation.

2784 Finite element simulation of the feasibility experiment

279 4.1 FSR finite element modeling

The corresponding FSR FE projects were performed in Simufact.Forming

281 software, which has been successfully employed in t numerical analysis of cross-wedge 282 rolling process $[26,27]$ and skew rolling process $[2,28]$, and their FE results have a 283 good agreement with experimental results. The FSR finite element model is based on 284 the actual situations of the feasibility experiment, and their parameters are the same.

285 The material of the workpiece is C45. Its material data were taken from 286 Simufact.Material. The properties (i.e., density, Young's modulus and Poisson's ratio) 287 were set as default. The flow stress of C45 steel was defined by Eq. 1, in which $\sigma_{F}$ is 288 the flow stress $(\mathrm{MPa}), \varphi$ is the effective strain $(-)$ and $T$ is the temperature $\left({ }^{\circ} \mathrm{C}\right)$ :

$$
\sigma_{F}=2589.85 e^{-0.003125 T} \varphi^{(0.00004466 T-0.10127)} e^{(-0.000027 T+0.0008183) / \varphi} \dot{\varphi}^{(0.00015 T-0.002749)}
$$

The friction coefficients between tools and workpiece were modeled by Shear model (two rollers were 0.8, two tube guides were 0.2. [2] The temperature of tools

292 (rollers, guides) was constantly maintained at $300{ }^{\circ} \mathrm{C}[2]$. The initial temperature of 293 workpiece was $1050{ }^{\circ} \mathrm{C}$ and the coefficient of heat transfer between tools and workpiece was $10 \mathrm{~kW} / \mathrm{m}^{2} \mathrm{~K}$ [2]. Besides, the mesh of billet was created by ringmesh mesher, whose element size equals to $6 \mathrm{~mm}$ and will be automatically reconstruected if the effective

296 strain increases by 0.4 [2]. The modeled FSR finite element model is displayed in Fig. 29713. 


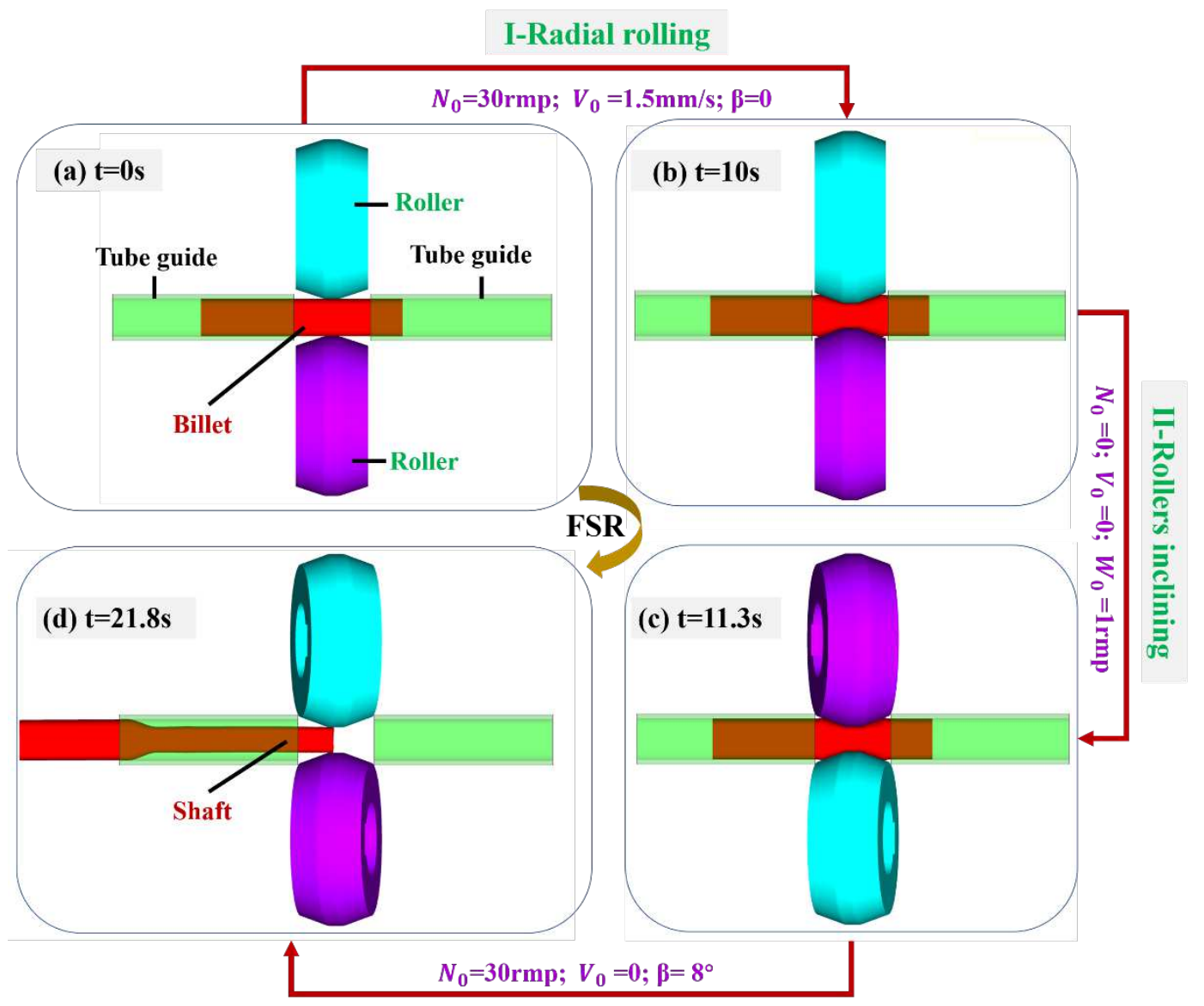

IIII-Skew rolling

Fig. 13 FSR finite element model of a $\Phi 80 \mathrm{~mm}$ single-step shaft

4.2 FSR finite element model validating

The FSR FE model was validated by a method of comparing the final geometry parameters of the rolled shaft between physical and FE results which was used in the study of Zhou [29]. The geometric parameters of FE model and experimentation were measured in the Geomagic Quality software. The comparison results include total

305 length $L$, side cavity angle $\gamma$, minimum diameter $D_{\min }$ and maximum diameter $D_{\max }$ of 306 the rolled bar.

307 The geometry comparison is shown in Table.2. The maximum relative deviation 308 (relative to physical result) of four geometric parameters is side cavity angle $\gamma$ with a 309 value equal to $2.1 \%$, and all these deviations within the $10 \%$ range, so that the FSR 310 finite element model can be considered reliable. 
Table 2 Geometry comparison between physical and FE results

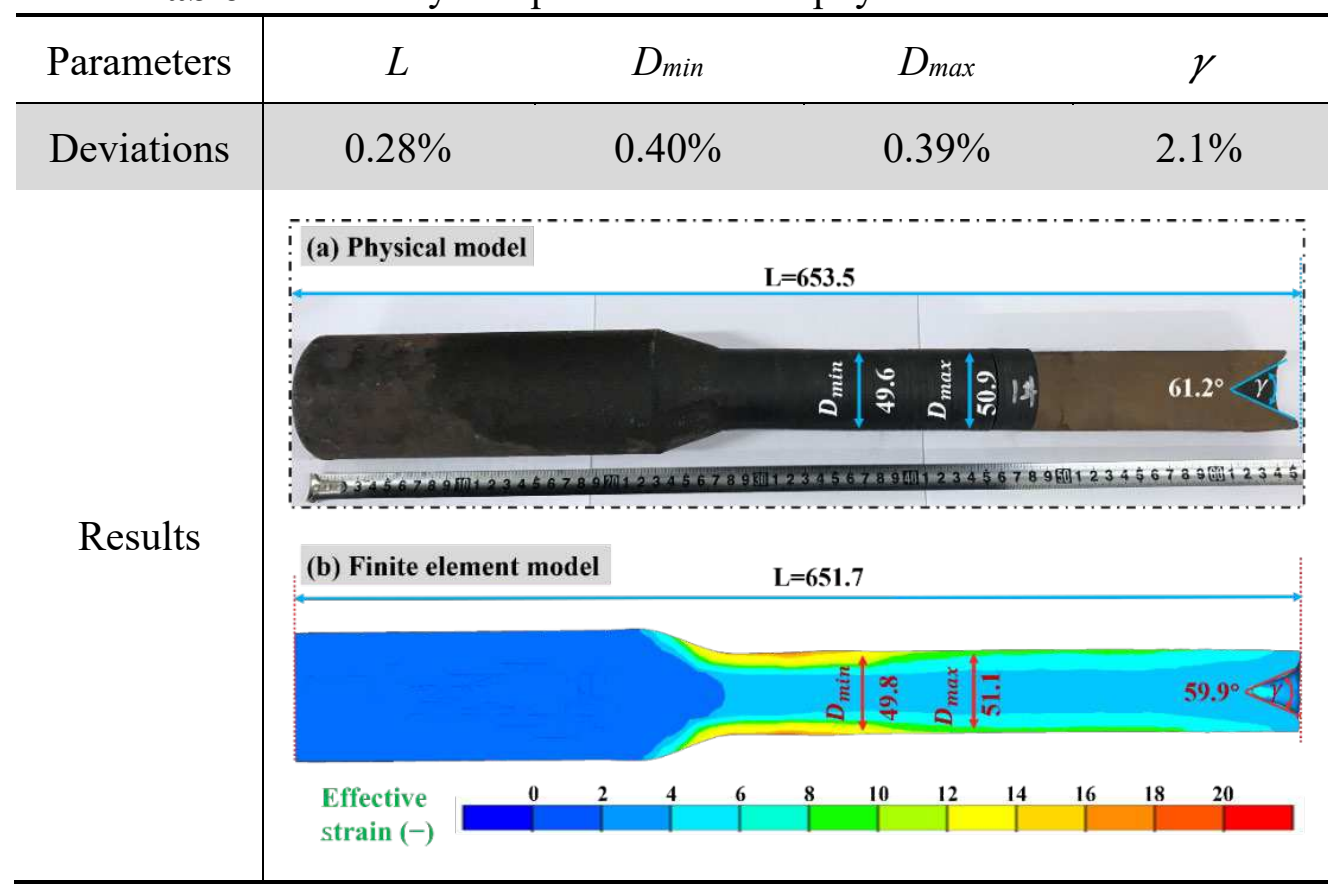

\subsection{Results and discussion}

\subsubsection{Deformation characteristics}

In the application of finite element software, the FSR deformation process can be

316 extracted from FE simulation results. As shown in Fig. 14, at the stage of rollers

317 inclining, the workpiece has a slight deformation. Therefore, it can be obtained that the

318 main forming stages of FSR process are radial rolling stage and skew rolling stage. At

319 the radial rolling stage, the workpiece is bit into a groove and deformed on two sides.

320 The metals in contacting zone are radially compressed and axially elongated, and the

321 axial movements of workpiece are at a same speed $V_{R I}$ but with opposite directions.

322 During the skew rolling stage, two rollers contact with the workpiece only in one side,

323 and the rolling workpiece radially rotates and axially feeds automatically under the

324 function of friction component because two rollers are inclined. 


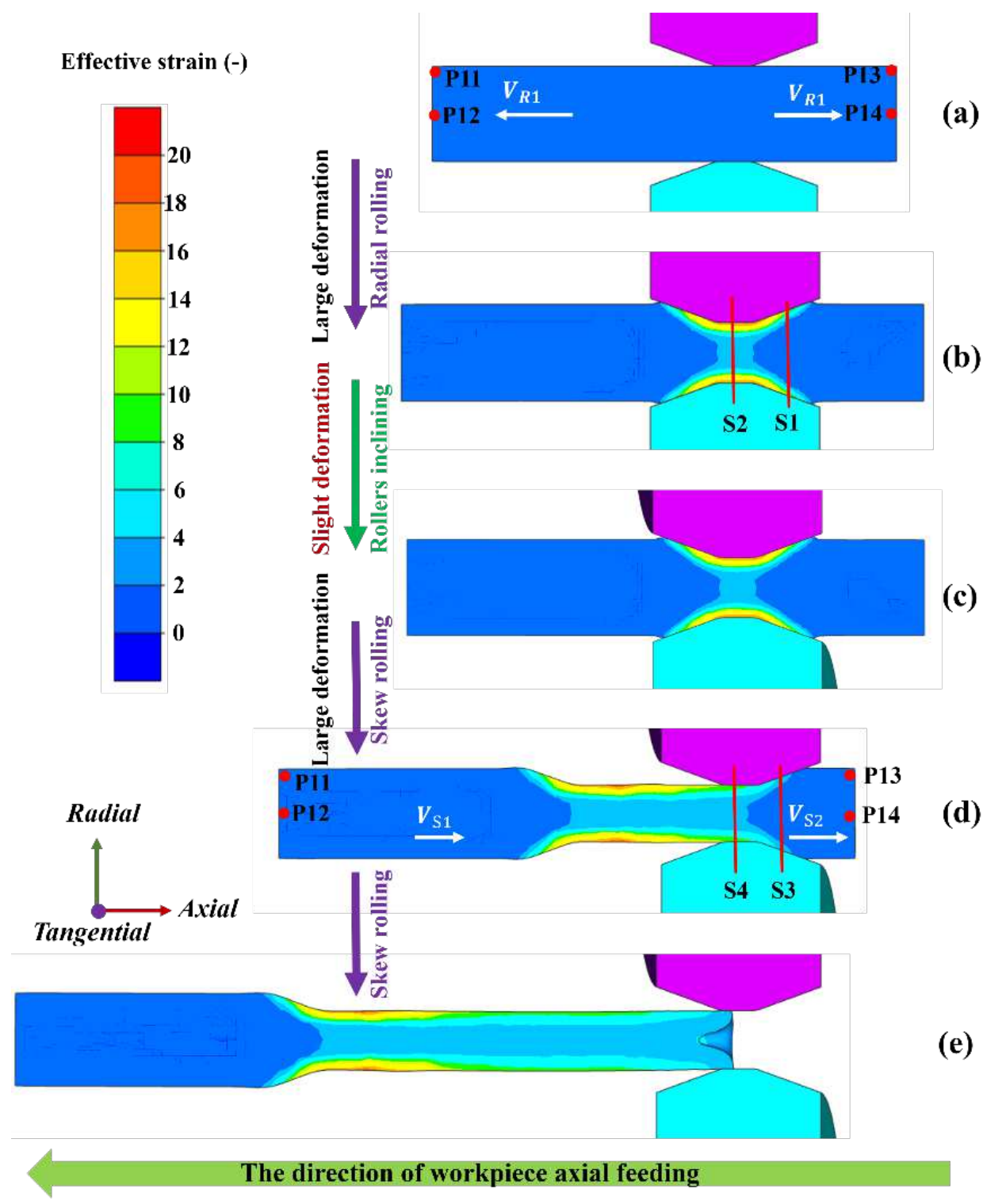

Fig. 14 Rolling stages and strain distributions of the $\Phi 80 \mathrm{~mm}$ single-step FSR shaft: (a) beginning; (b) ending of radial rolling / beginning of rollers inclining; (c) ending of rollers inclining / beginning of skew rolling; (d) middle of skew rolling; (e) ending

In fact, the deformation characteristics of FSR have some similarities to the CWR

331 process which was described in the study of $\mathrm{Xu}$ [30]. The workpiece is radially knifed

332 primarily and then stretched axially. We can think that, the radial rolling stage is similar

333 to the knifing stage in CWR, while the skew rolling stage is similar to the stretching 334 stage of CWR.

335 Since the equal-diameter bar of the rolled shaft is formed by skew rolling, another

336 feature of the FSR deformation is that the major forming stage of the FSR forming is 337 skew rolling stage. To be specific, the shaft is formed by the roller' forming zone and 
338 sized by the roller' sizing zone. Therefore, we can come to a conclusion that the skewing 339 angle $\beta$, forming angle $\alpha$ and sizing length $L$ are extremely important to FSR process.

\section{0}

\subsubsection{Central quality of workpiece}

According to the experiences of skew rolling and cross-wedge rolling, the Mannesmann hole [25] may occur in the center of FSR workpiece and cause the failure of products. To obtain the evolutions of stress and ductile damage, four transverse sections named S1, S2, S3, S4 were selected to do a analyze. As signed in Fig. 14, S1 and S3 are the forming sections of radial rolling and skew rolling while S2 and S4 are the sections after rolling.

Figure 15 shows the distribution of FSR stress. At the radial rolling stage, the central materials are exerted two tension stress and one compression stress. More specifically, the radial stress is a compressive stress which gradually reduces from the surface to the center, and the tangential or axial stress is a tensile stress which locally concentrated in the workpiece center.

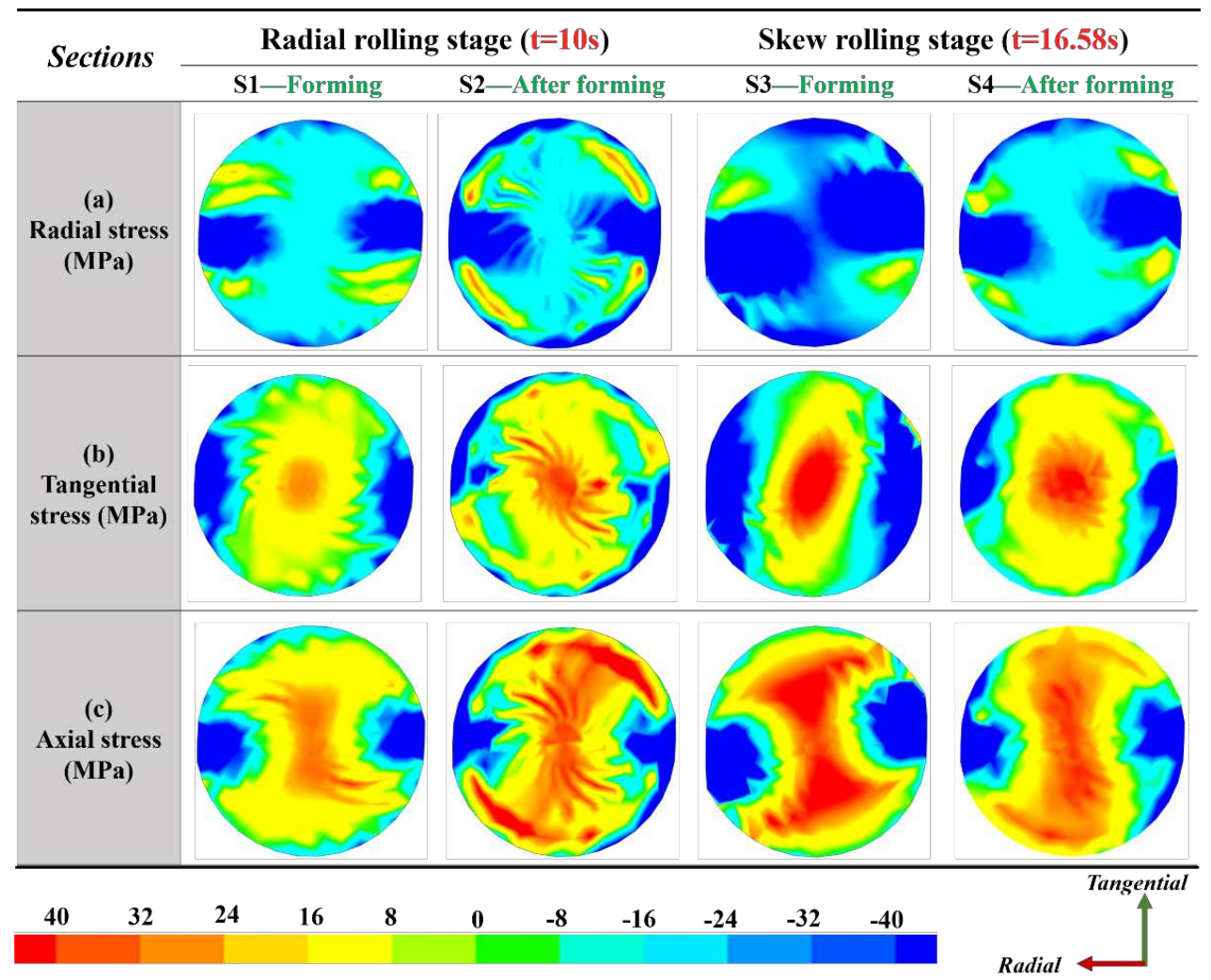


During the skew rolling stage, the stress distribution characteristics are identical to the rolling stage that two tension stress and one compression stress exist in the central region. Compared to the radial rolling stage, the tangential tension stress and axial tension stress at skew rolling stage become bigger. The radial stress of the central zone is compressive with a relatively small value of approximate $20 \mathrm{MPa}$ while tangential stress and axial stress are tensile with a relatively larger value exceed 40MPa. Since the stress distribution state of the center is tension in two orientations and one compression in one orientation which may causes the generation of micro-cracks, it can be concluded that the FSR process is susceptible to central crack.

Three typical damage models were used to predict the damage state in FSR process

364 (Fig. 16). Cockcroft and Latham [31] considered that the damage value is equal to the ratio of maximal principal stress and effective stress. Oyane [32] proposed a ductile damage model which based on the characteristics of porous materials. Ayada et al. [33] held an opinion that ductile fracture only depends on the history of stress triaxiality.

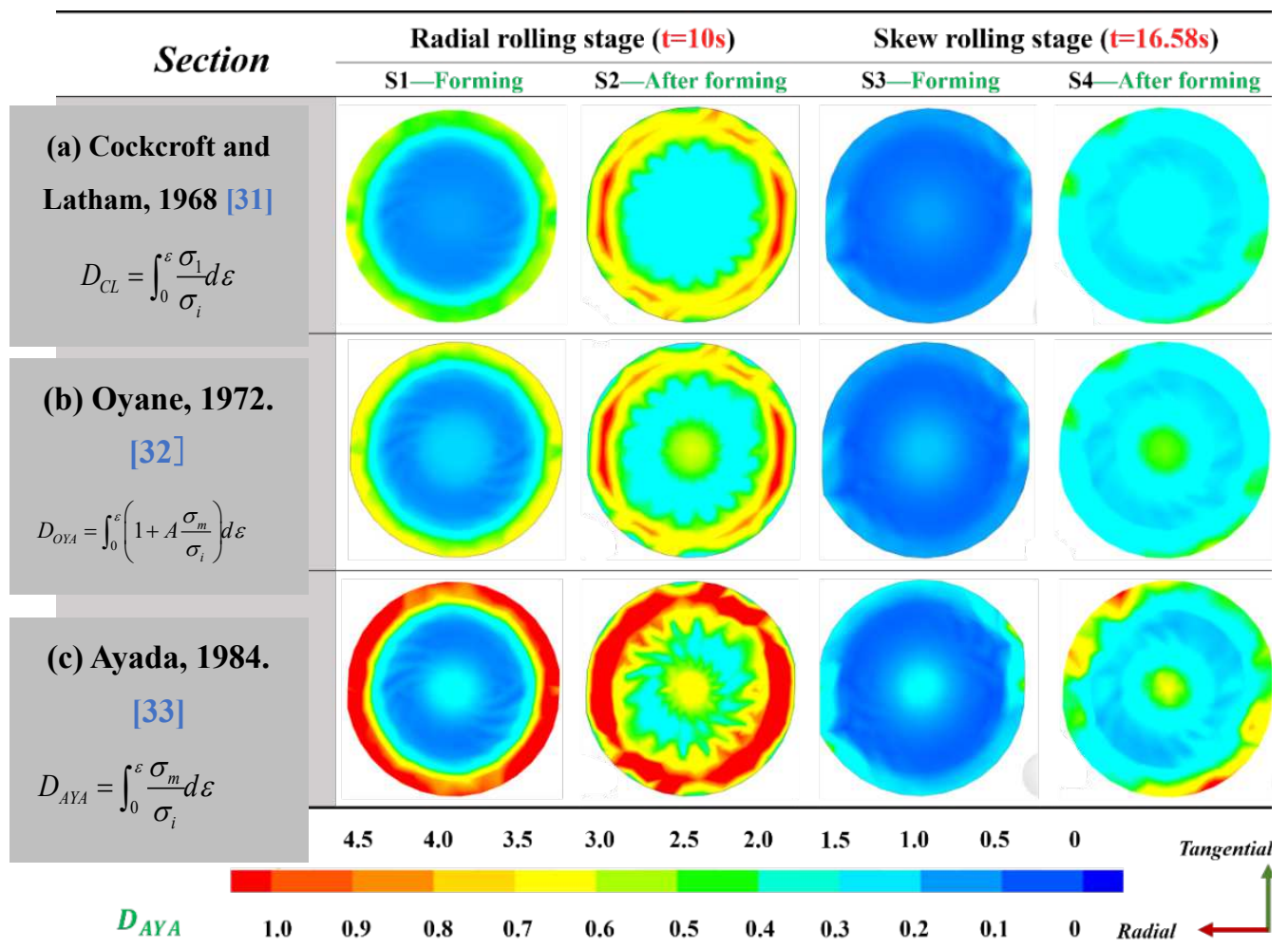

Fig.16 Ductile damages of FSR workpiece: (a) Cockcroft and Latham [31]; (b) Oyane [32]; (c) Ayada [33], in which $\varepsilon$ is effective strain, $\sigma_{l}$ is maximal principal stress, $\sigma_{i}$ is

371 effective stress, $\sigma_{l}$ is mean stress, A is a material coefficient $(0.424)$ [34] 
The ductile damages are calculated by the functions demonstrated in Fig. 16.

373 Furthermore, in order to get the damage distribution from FE software, the user

374 subroutine of Simufact.Forming was employed to implement these criteria, so the

375 damage values can unconditionally update at every increment and visible analyzed in

376 the postprocessor. As shown in Fig. 16, it can be obviously observed that the ductile

377 damages of three criterions have some commons: 1) there are damage concentrations

378 in the central region; 2) the ductile damages increase evidently at the stage radial rolling

379 and skew rolling. These findings are consistent with the stress distribution conditions

380 analyzed above, so it can be obtained that the FSR process has a trend of central

381 cracking. In addition, although it is shown that there are also some large ductile

382 damages in the outer region, it can be explained that the outer workpiece undergoes a

383 large tensile stress.

384 However, it is noteworthy that the damage distribution can reveal the trend of 385 central crack which may be occured under unreasonable parameters, but it cannot be 386 judged that the simulation results are inconsistent with the experiment because the 387 predicted damage value may not reach the fracture threshold value.

\subsubsection{Axial feeding velocity}

The axial feeding velocity of the workpiece directly determines the FSR production efficiency. Four tracking points (P11, P12, P13 and P14) are selected, and

391 their axial velocities are demonstrated in Fig. 22. During the radial rolling stage, the 392 axial feeding velocities of the workpiece from inlet to outlet side have the same value $393 V_{R I}$ but in different directions. However, at the skew rolling stage, its value in inlet $\left(V_{S I}\right)$ 394 and outlet side $\left(V_{S 2}\right)$ are not the same. Quantitative analysis reveals that the axial 395 moving speed of radial rolling stage is relatively small with a value of approximately $3962 \mathrm{~mm} / \mathrm{s}$. At the skew rolling stage, the value of axial moving speed has a larger number with an average value of about $28.5 \mathrm{~mm} / \mathrm{s}$ in outlet side. 


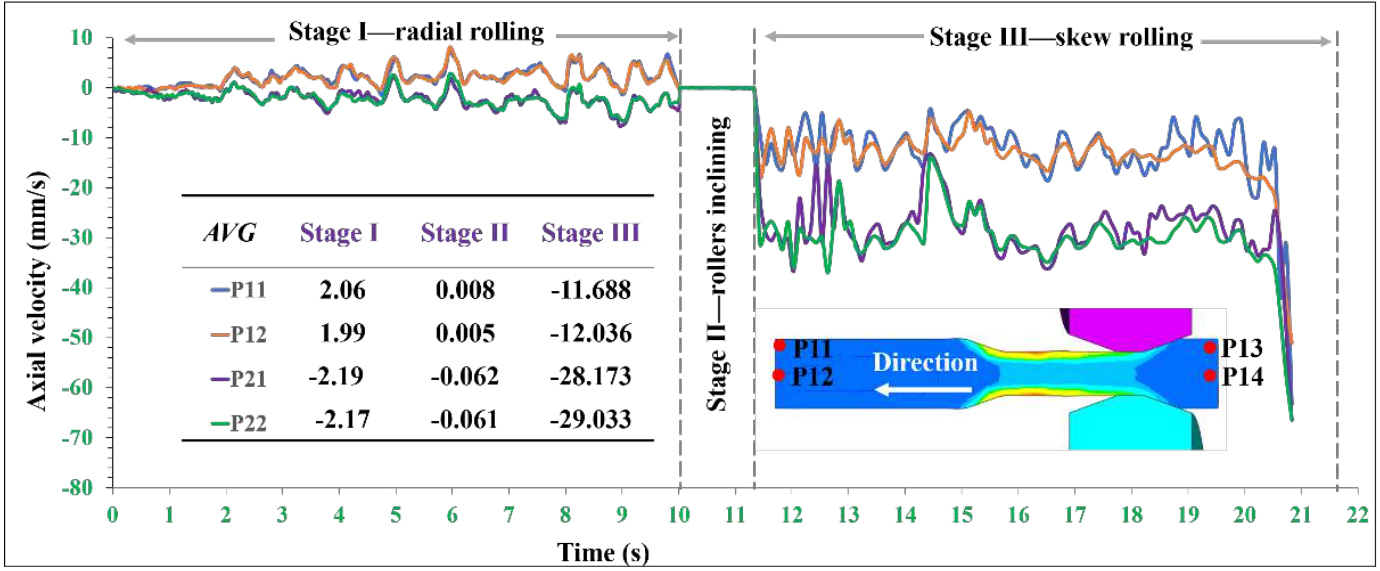

Fig.17 Rolling speed and duration of FSR process

Actually, the axial feeding velocity of workpiece is affected by rotating speed $N_{0}$, forming angle $\alpha$ and skewing angle $\beta$. The rotating speed $N_{0}$ of this study is only $30 \mathrm{rpm}$, which is relatively low in skew rolling. However, the total rolling time is as short as 20 seconds. It can be concluded that the production of FSR is efficient.

\subsubsection{Temperature distribution}

The temperature distribution is investigated as shown in Fig. 18. It can be observed that the temperature of the workpiece is relatively stable. Meanwhile, it can be noticed that the temperature increases locally at the working area because the deformation and friction cause the heat generation. The surface of billet have a temperature drop, which can be explained that it undergoes a local cooling because the heat is dissipated to the air, but fortunately the temperature is still in the range of the hot deformation. What's more, since the temperature drops slowly and the rolling time is short that the workpiece temperature can be stabilized within a hot formability range, so the billet of FSR process need to be heated only once, which obviously reduce energy consumption. 
(a)

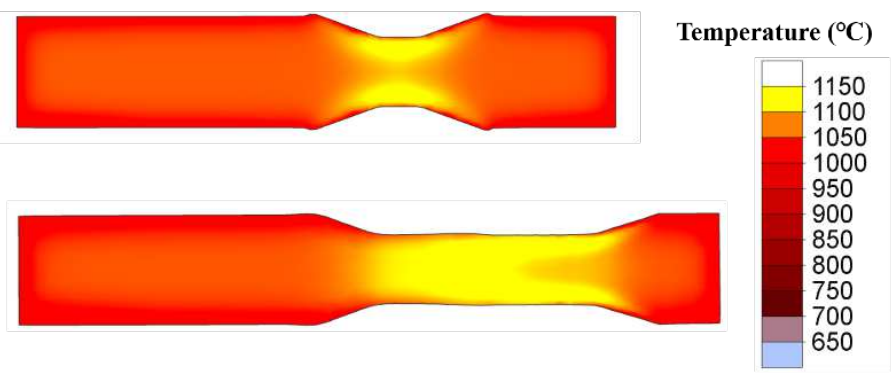

(c)

Fig. 18 Temperature distributions of FSR workpiece: (a) ending of radial rolling stage

(b) middle of skew rolling stage; (c) ending of skew rolling stage

\subsubsection{Rolling force and rotating torque}

The force parameters of rolling force and rotating torque are the basic data in equipment designment. As shown in Fig. 19, at the roller leveling stage, both the rolling

421 force and rotating torque are very small, which further verify that the workpiece have a very slight deformation at this stage. However, at the forming stages (radial rolling stage and skew rolling stage), the rolling force and torque change correspondingly with relatively large values. Concretely, the rolling force differs little with a value about 150 $\mathrm{kN}$. The rotation torque of the spindle motor varies greatly with a maximum value of approximate to $8700 \mathrm{Nm}$.

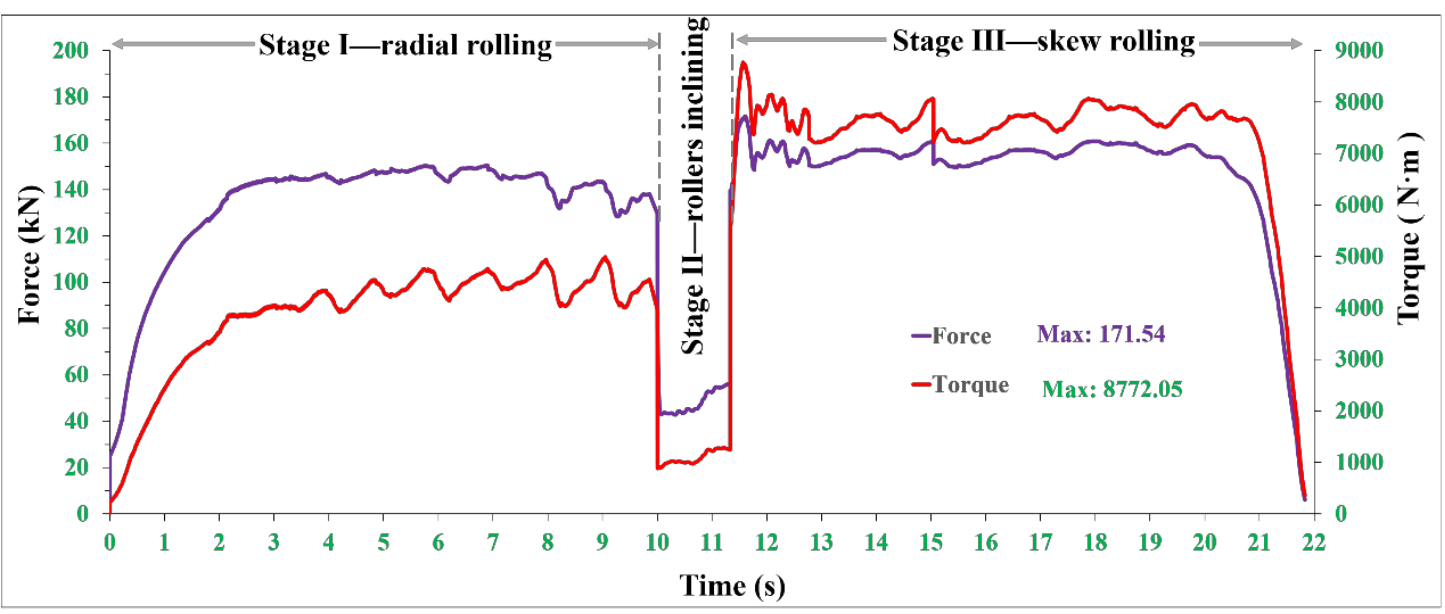




\section{Application exploration}

The above studies in this paper are based on a simple single-step shaft, but in fact

432 the shapes of large shafts are changed variously. In order to explore the industrial 433 applications, some physical experiments were carried out with different rollers to form 434 various parts in the laboratory (Fig. 20). Because it can form different shafts by same 435 rollers, these flexible experiments were conducted conveniently. There are two types of 436 parts were produced: bars and step-shafts.

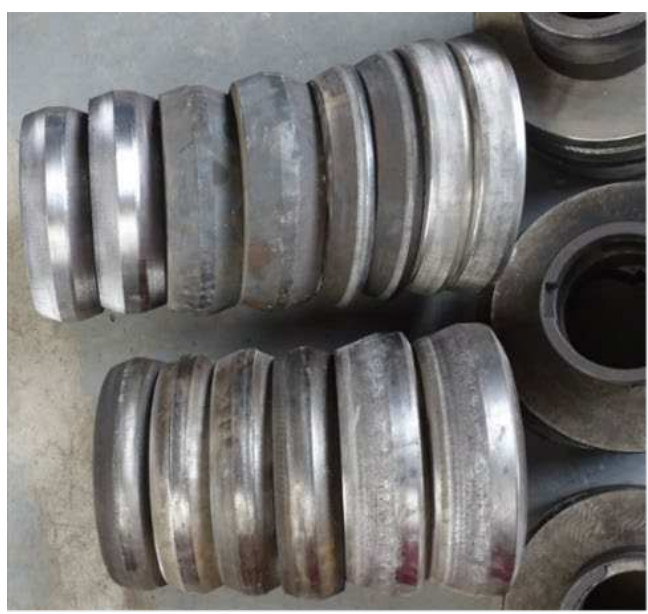

(a) Rollers

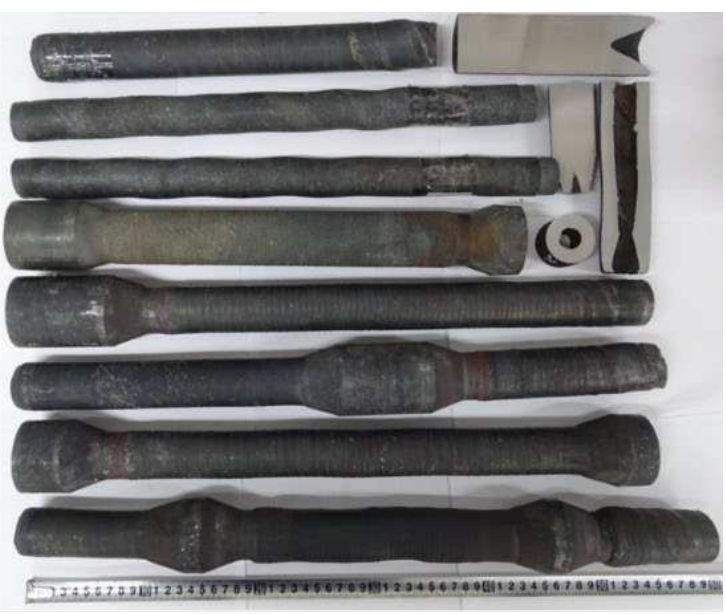

(b) Shafts

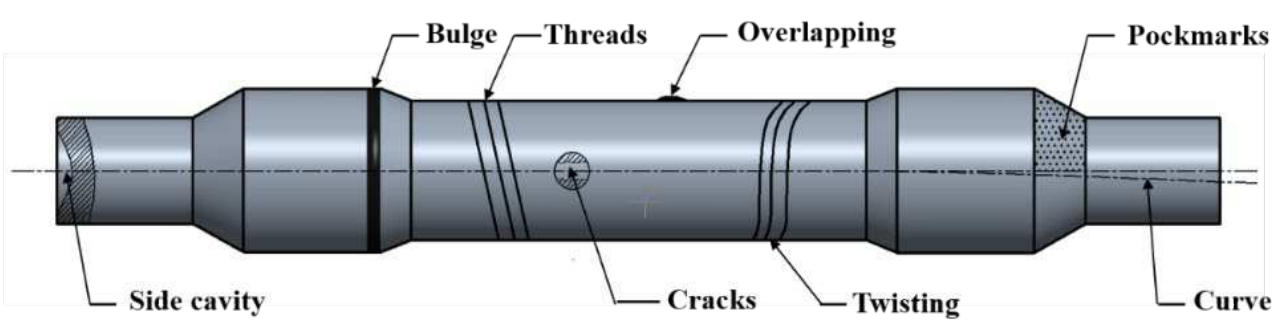

(c) Defects

Fig. 20 Exploratory experiments were accomplished through (a) different rollers and (b) shafts, and (c) FSR defects appear on the rolled shafts As shown in Fig. 20a, the rollers have different geometries including symmetric rollers and tapered rollers (the tapered roller is generally used in copy skew rolling and CNC Skew rolling, as Fig. 1 show), and their parameters of sizing length $L$ and forming angle $\alpha$ are also varied in different values. By carrying out the experiments, we found that the tapered roller is not suitable for the FSR process because the step bulge appeared in the radial rolling process due to asymmetric deformation. Besides, the roller 
material and its heat treatment process are very important because the FSR roller stands

447 high temperature, rapid rotation, and large rolling force. Moreover, the small forming 448 angle $\alpha$ and large skewing angle $\beta$ are favorable for billet feeding, but conversely it will increase the possibility of central cracking. The big sizing length $L$ can directly reduce 450 the surface threads, but will result in the increase of the rolling force. Therefore, a 451 process window needs to be established in further studies.

The shaft with multiple steps was rolled and displayed in Fig. 20b. Attention 453 should be paid, there are some forming defects that evidently appeared in the formed 454 products. These defects are summarized in Fig. 20c, in which side cavity, surface threads, pockmarks and central cracks are the most noteworthy limitations. These defects limit the application of the FSR process and need to be solved in future studies.

\section{Conclusions}

-A novel method named flexible skew rolling (FSR) has been proposed and verified through physical experiment and FE simulation. The FSR process can be expected to produce large shafts in small equipment and form various shafts with same rollers.

$462 \cdot$ The FSR rolled shaft has a maximum deviation of $0.99 \mathrm{~mm}$. Although there is a tendency of center cracks as FE results predict, the physical shaft is free from internal cracks and its microstructure and mechanical properties are generally improved.

-The FSR forming defects are summarized by an exploratory experiment of 466 forming various shafts with different rollers, of which the most noteworthy limitations 467 are central cracks, surface threads and side cavity, so that the generation mechanisms and optimization methods for FSR defects need to be investigated in further studies.

- The deformation characteristics of the FSR process are similar to cross-wedge rolling that the workpiece is radially compressed initially and then stretched axially, but 471 the movements of FSR rollers are much similar to piercing rolling that the inclined 472 rollers drive the workpiece rotates circularly and moves axially.

$473 \cdot$ FSR process has an optimistic efficiency with an axial feeding velocity of 28.5 
$\mathrm{mm} / \mathrm{s}$ in outlet side, which is beneficial to keep the temperature relatively stable, so the workpiece needs to be heated only once.

-The loading of the FSR process is relatively light that the maximum radial rolling force is about $150 \mathrm{kN}$ and the maximum rotation torque is about $8700 \mathrm{Nm}$ of a $\Phi 80$ mm shaft.

\section{Compliance with Ethical Standards}

\section{Acknowledgments}

This work is supported by the National Key R\&D Program of China (Grant No. 2018YFB1307900). This work is funded by the National Natural Science Foundation of China (Grant No. 51875036).

\section{Conflict of interest statement}

We declare that we have no financial and personal relationships with other people or organizations that can inappropriately influence our work, there is no professional or other personal interest of any nature or kind in any product, service and/or company that could be construed as influencing the position presented in, or the review of, the manuscript entitled.

\section{Ethical approval}

This article does not contain any studies with human participants or animals performed by any of the authors.

\section{Informed consent}

All the authors listed have approved the manuscript that is enclosed.

\section{Authors' contributions}

Longfei Lin: Software, Investigation, Validation, Methodology, Writing-Original Draft. Baoyu Wang: Project administration, Supervision, Funding acquisition. Jing Zhou: Methodology, Writing-Reviewing \& Editing. Jinxia Shen: Data Curation, Writing-Reviewing \& Editing.

\section{Availability of data and materials}

The datasets generated and/or analysed during the current study are available from 
502 the corresponding author on reasonable request.

\section{Consent to participate}

$504 \quad$ Applicable.

\section{Consent to publish}

$506 \quad$ Applicable.

\section{References}

508 [1] Ji H, Liu J, Fu X, Tang X, Wang B, Huang X (2017) Finite element analysis and

[2] Pater Z, Tomczak J, Lis K, Bulzak T, Shu X (2020) Forming of rail car axles in a experiment on multi-wedge cross wedge rolling for asymmetric stepped shaft of C45. Journal of Central South University 24: 854-860. https://doi.org/10.1007/s11771-017-3487-8

$$
\text { CNC skew rolling mill. Arch Civ Mech Eng 20:69. }
$$
https://doi.org/10.1007/s43452-020-00075-5

[3] Yang C, Hu Z (2016) Research on the ovality of hollow shafts in cross wedge rolling with mandrel. Int $J$ Adv Manuf Tech 83:67-76. https://doi.org/10.1007/s00170-015-7478-3

[4] Li J, Wang B, Fang S, Chen P (2020) A new process chain combining cross-wedge rolling and isothermal forging for the forming of titanium alloy turbine blades. Int J Adv Manuf Tech 108:1827-1838. https://doi.org/10.1007/s00170-020-05451-2

[5] Zwanenburg W (2006) Degradation processes of switches \& crossings. Institution of Engineering \& Technology International Conference on Railway Condition Monitoring IET :115-119. https://doi.org/10.1049/ic:20060054

[6] Lee Y, Lee S, Tyne C, Joo B, Moon Y (2011) Internal void closure during the forging of large cast ingots using a simulation approach. J Mater Process Tech 211(6):1136-1145. https://doi.org/10.1016/i.jmatprotec.2011.01.017

[7] Du S, Li Y, Song J (2015) Optimization of forging process parameters and anvil design for railway axle during high-speed forging. Asme International Mechanical Engineering Congress \& Exposition. https://doi.org/10.1115/IMECE2015-50695

[8] Ghaei A, Movahhedy M, Taheri K (2005) Study of the effects of die geometry on deformation in the radial forging process. J Mater Process Tech 170(1-2):156-163. https://doi.org/10.1016/j.jmatprotec.2005.04.100

[9] Zou J, Ma L, Jia W, Le Q, Qin G,Yuan Y (2021) Microstructural and mechanical response of ZK60 magnesium alloy subjected to radial forging. J Mater Sci Technol 83:228-238. https://doi.org/10.1016/j.jmst.2020.11.080

[10] Romanenko V, Stepanov P, Kriskovich S (2018) Production of hollow railroad 
axles by screw piercing and radial forging. Metallurgist 61:873-877. https://doi.org/10.1007/s11015-018-0579-0

[11] Peng W, Zheng S, Chiu Y, Shu X, Zhan L 2016 Multi-wedge cross wedge rolling process of $42 \mathrm{CrMo} 4$ large and long hollow shaft. Rare Metal Materials and Engineering 45(4):836-842. https://doi.org/10.1016/S1875-5372(16)30084-4

[12] Pater Z (2020) Numerical analysis of the cross-wedge rolling process of a railway

[13] Houska M (1999) Experiment and finite-element analysis of axial feed bar rolling (AVQ). The 6th International Conference on Technology of Plasticity:1523-1538.

[14] Xu C, Liu G, Ren G, Shen Z, Ma C, Ren W (2007) Finite element analysis of axial feed bar rolling. Acta Metallurgica Sinica 20(006):463-468. https://doi.org/10.1016/S1006-7191(08)60011-3

[15] Li C, Su X, Hu Z (2006) Status and research of axle forming methods for railway shafts. Metallurgical Equipment 6:5-8. In Chinese. https://doi.org/10.3969/j.issn.1001-1269.2006.06.002

[16] Hu Z, Zhang K, Wang B, Shu X, Yang C (2004) Technology and simulation of part rolling by cross wedge rolling. Metallurgical Industry Press, Beijing. In Chinese,

[17] Pater Z, Tomczak J, Bulzak T (2020) Problems of forming stepped axles and shafts in a 3-roller skew rolling mill. J Mater Res Technol 9(5):10434-10446. https://doi.org/10.1016/j.jmrt.2020.07.062

[18] Wang B, Lin L., J. Liu, C. Yang (2021) Device and method for forming shaft part by two-roller flexible skew rolling. European Patent No. 3733322.

[19] Wang B, Lin L, Wang S. Yang C, Liu S, Zhang H (2021) Flexible skew rolling mill with dual-rotatable-shafts. United State Patent No. 16/906729.

[20] Pater Z, Kazanecki J (2006) Thermo-mechanical analysis of piercing plug loads in the skew rolling process of thick-walled tube shell. Metallurgy and foundry engineering 32(1):31. https://doi.org/10.7494/mafe.2006.32.1.31

[21] Gamin Y, Akopyan T, Koshmin A, Dolbachev A, Goncharuk A (2020) Microstructure evolution and property analysis of commercial pure $\mathrm{Al}$ alloy processed by radial-shear rolling. Arch Civ Mech Eng 20:143. https://doi.org/10.1007/s43452-020-00143-w

[22] Shen J, Wang B, Zhou J, Lin L, Feng P, Investigation on the inner hole spiralgroove of cross wedge rolling of hollow shafts with mandrel. Int J Adv Manuf Technol 110:1773-1787. https://doi.org/10.1007/s00170-020-05801-0

[23] Shu X, Shi J, Chen Ji, Yang H (2021) Effect of process parameters on surface quality of shafts parts formed by warm cross wedge rolling. Int J Adv Manuf Tech 
[24] Feng P, Yang C, Wang B, et al (2021) Formability and microstructure of TC4 titanium alloy hollow shafts formed by cross-wedge rolling with a mandrel. Int J Adv Manuf Tech 114:365-377. https://doi.org/10.1007/s00170-021-06635-0

[25] Ghiotti A, Fanini S, Bruschi S, Bariani P (2009) Modelling of the Mannesmann effect. CIRP Annals - Manufacturing Technology, 58(1):255-258. https://doi.org/10.1016/j.cirp.2009.03.099

[26] Tofil A, Tomczak J, Bulzak T (2015) Numerical and experimental study on producing aluminium alloy 6061 shafts by cross wedge rolling using a universal rolling mill. Arch Metall Mater 60(2):801-807. https://doi.org/10.1515/amm$\underline{2015-0210}$

[27] Pater Z, Tomczak J, Bulzak T (2016) Cross-wedge rolling of driving shaft from titanium alloy Ti6A14V. Key Eng Mat 687:125-32. https://doi.org/10.4028/www.scientific.net/KEM.687.125

[28] Lis K, Wójcik U, Pater Z (2016) Numerical analysis of a skew rolling process for producing a crankshaft preform. Open Engineering 6:581-584. https://doi.org/10.1515/eng-2016-0087

[29] Zhou X, Shao Z, Zhang C, Sun F, Zhou W, Hua L, Jiang J, Wang L (2020) The study of central cracking mechanism and criterion in cross wedge rolling. Int $\mathrm{J}$ Mach Tool Manu 159:103647. https://doi.org/10.1016/j.ijmachtools.2020.103647

[30] Huang X, Wang B, Zhou J, Ji H, Mu Y, Li J (2017) Comparative study of warm and hot cross-wedge rolling: numerical simulation and experimental trial. Int $\mathrm{J}$ Adv Manuf Technol 92:3541-3551. https://doi.org/10.1007/s00170-017-0399-6

[31] Zhou J, Yu Y, Zeng Q (2014) Analysis and experimental studies of internal voids in multi-wedge cross wedge rolling stepped shaft. Int J Adv Manuf Technol 72:1559-1566. https://doi.org/10.1007/s00170-014-5768-9

[32] Novella M, Ghiotti A, Bruschi S, Bariani P (2015) Ductile damage modeling at elevated temperature applied to the cross wedge rolling of AA6082-T6 bars. J Mater Process Tech 222:259-267. https://doi.org/10.1016/j.jmatprotec.2015.01.030

[33] Ayada M, Higashino T, Mori K (1984) Central bursting in extrusion of inhomogeneous materials. In Proceedings of the First International Conference on Technology of Plasticity:553-558.

[34] Pater Z, Tomczak J, Bulzak T, Wójcik U, Walczuk P (2019) Assessment of ductile fracture criteria with respect to their application in the modeling of cross wedge rolling. J Mater Process Tech 278:116501. https://doi.org/10.1016/j.jmatprotec.2019.116501 